\title{
Redox flow batteries: a review
}

\author{
Adam Z. Weber • Matthew M. Mench • \\ Jeremy P. Meyers • Philip N. Ross • \\ Jeffrey T. Gostick - Qinghua Liu
}

Received: 12 July 2011/Accepted: 16 August 2011/Published online: 2 September 2011

(C) The Author(s) 2011. This article is published with open access at Springerlink.com

\begin{abstract}
Redox flow batteries (RFBs) are enjoying a renaissance due to their ability to store large amounts of electrical energy relatively cheaply and efficiently. In this review, we examine the components of RFBs with a focus on understanding the underlying physical processes. The various transport and kinetic phenomena are discussed along with the most common redox couples.
\end{abstract}

Keywords Flow battery $\cdot$ Redox $\cdot$ Regenerative fuel cell . Flow cell $\cdot$ Vanadium

\section{List of symbols}

$\alpha_{k, p} \quad$ Interfacial surface area between phases $k$ and $p$ per unit volume $\left(\mathrm{cm}^{-1}\right)$

$c_{i} \quad$ Concentration of species $\left(\mathrm{mol} / \mathrm{cm}^{3}\right)$

$d_{\mathrm{f}} \quad$ Fiber diameter $(\mathrm{cm})$

$D_{i} \quad$ Fickian diffusion coefficient of species $i$ in a mixture $\left(\mathrm{cm}^{2} / \mathrm{s}\right)$

\section{A. Z. Weber $(\bowtie) \cdot$ P. N. Ross}

Environmental Energy Technologies Division, Lawrence

Berkeley National Laboratory, Berkeley, CA 94720, USA

e-mail: azweber@lbl.gov

M. M. Mench · Q. Liu

Department of Mechanical, Aerospace and Biomedical

Engineering, University of Tennessee, Knoxville, TN, USA

M. M. Mench

Energy and Transportation Science Division, Oak Ridge

National Laboratory, Oak Ridge, TN 37831, USA

J. P. Meyers

Department of Mechanical Engineering,

The University of Texas, Austin, TX, USA

J. T. Gostick

Department of Chemical Engineering, McGill University,

Montreal, QC, Canada
$E^{0} \quad$ Standard cell potential (V)

$E_{\text {eq }} \quad$ Equilibrium cell potential (V)

F Faraday's constant, 96487 C/equiv

$i \quad$ Superficial current density $\left(\mathrm{A} / \mathrm{cm}^{2}\right)$

$i_{0} \quad$ Exchange current density $\left(\mathrm{A} / \mathrm{cm}^{2}\right)$

$i_{h, k-p} \quad$ Transfer current density of reaction $h$ per interfacial area between phases $k$ and $p\left(\mathrm{~A} / \mathrm{cm}^{2}\right)$

$k \quad$ Permeability $\left(\mathrm{m}^{2}\right)$

$k^{0} \quad$ Standard rate constant, varies

$m \quad$ Valence state

$n \quad$ Valence state or number of electrons transferred in a reaction

$\mathbf{N}_{i} \quad$ Superficial flux density of species $i\left(\mathrm{~mol} / \mathrm{cm}^{2} \mathrm{~s}\right)$

$p \quad$ Pressure $(\mathrm{Pa})$

$r_{l, k-p} \quad$ Rate of reaction $l$ per unit of interfacial area between phases $k$ and $p\left(\mathrm{~mol} / \mathrm{cm}^{2} \mathrm{~s}\right)$

$R \quad$ Ideal-gas constant, $8.3143 \mathrm{~J} / \mathrm{mol} \mathrm{K}$

$R_{g, k} \quad$ Rate of homogenous reaction $g$ in phase $k(\mathrm{~mol} /$ $\mathrm{cm}^{3} \mathrm{~s}$ )

$R_{i, j} \quad$ Resistance of resistor $i, j$ in Fig. 10 where ct stands for charge-transfer $\left(\Omega \mathrm{cm}^{2}\right)$

$s_{i, k, l} \quad$ Stoichiometric coefficient of species $i$ in phase $k$ participating in reaction $l$

$t \quad$ Time (s)

$T \quad$ Absolute temperature $(\mathrm{K})$

$u_{i} \quad$ Mobility of species $i\left(\mathrm{~cm}^{2} \mathrm{~mol} / \mathrm{J} \mathrm{s}\right)$

$\mathbf{v} \quad$ Superficial velocity $(\mathrm{cm} / \mathrm{s})$

$x \quad$ Stoichiometric coefficient

$y \quad$ Stoichiometric coefficient

$z_{i} \quad$ Valence or charge number of species $i$

Greek

$\alpha \quad$ Transfer coefficient

$\alpha_{i} \quad$ Transport coefficient of species $i\left(\mathrm{~mol}^{2} / \mathrm{J} \mathrm{cm} \mathrm{s}\right)$

$\varepsilon \quad$ Porosity 
$\varepsilon_{0} \quad$ Permittivity (F/cm)

$\xi \quad$ Electroosmotic coefficient

$\rho \quad$ Density $\left(\mathrm{g} / \mathrm{cm}^{3}\right)$

$\rho_{\mathrm{c}} \quad$ Charge density $\left(\mathrm{C} / \mathrm{cm}^{3}\right)$

$\sigma \quad$ Conductivity of the electronically conducting phase $(\mathrm{S} / \mathrm{cm})$

$\eta \quad$ Overpotential (V)

$\kappa \quad$ Conductivity of the ionically conducting phase $(\mathrm{S} / \mathrm{cm})$

$\mu \quad$ Viscosity (Pa s)

$\mu_{i} \quad$ (Electro)chemical potential of species $i(\mathrm{~J} / \mathrm{mol})$

$\Phi_{k} \quad$ Potential in phase $k(\mathrm{~V})$

$\psi_{i} \quad$ Permeation coefficient of species $i(\mathrm{~mol} / \mathrm{s} \mathrm{cm} \mathrm{bar})$

\section{Super/subscripts}

* Reference state

0 Solvent

1 Electronically conducting phase

2 Ionically conducting phase

$\mathrm{O}$ Oxidant

R Reductant

\section{Introduction}

Renewable-energy sources, such as solar and wind, are being deployed in larger numbers than ever before, but these sources are intermittent and often unpredictable. These characteristics limit the degree to which utilities can rely upon them, and, as such, renewables currently comprise a small percentage of the primary power sources on the US electrical grid. Analysis suggests that an electric grid could become destabilized if non-dispatchable renewable energy exceeds $20 \%$ of the energy-generation capacity without energy storage [1]. However, many utilities are mandating renewable portfolios approaching this level of deployment, thus there is a pressing need for storage technologies to complement and enable renewable standards. Other than capacitors, however, there is no way to store electrical energy as such. Instead, if electricity is to be stored, it must first be converted to some other form of energy. There are some technologies that enable practical storage of energy at their current levels of deployment, but only a very small fraction of North American power plants employ such technology [2]. To ensure that renewable energy succeeds in delivering reliable power to US consumers, the nation needs cost effective and reliable storage at the grid scale.

Conventional rechargeable batteries offer a simple and efficient way to store electricity, but development to date has largely focused on transportation systems and smaller systems for portable power or intermittent backup power; metrics relating to size and volume are far less critical for grid storage than in portable or transportation applications.
It therefore stands to reason that optimizing battery performance over a different set of variables might result in an implementation that delivers superior performance for reduced cost. Batteries for large-scale grid storage require durability for large numbers of charge/discharge cycles as well as calendar life, high round-trip efficiency, an ability to respond rapidly to changes in load or input, and reasonable capital costs [3]. Redox flow batteries (RFBs) or redox flow cells (RFCs), shown schematically in Fig. 1, promise to meet many of these requirements [4].

As shown in Fig. 1, a key component of RFBs is the ability to separate power and energy. The power is controlled by the stack while the energy is stored within the separated reactants. Thus, one can optimize over a greater range of variables and storage can be increased with relatively ease and minimal cost compared to the stack, which is typically the most expensive system component. To examine the technologies that are under development to meet the cost requirements of the marketplace and enable wide-scale storage, we consider the existing portfolio of RFB storage technologies and the possibilities of each. To that end, we introduce the various technologies and discuss in more depth the general attributes and concerns facing RFBs. The overall purpose of this review is to examine systemic issues for the field of RFBs, and not just examine a specific chemistry or the various proposed RFBs. Excellent reviews of these latter issues and energy storage for the grid in general can be found in the literature [5-8]. The structure of this paper is as follows.

After an introduction and short overview of the various major RFBs, the kinetic and transport issues are examined in turn. Next, some overall electrode/cell modeling and designs are reviewed. Finally, some comments about future research needs are made. It should be noted that this review is focused on cell-level issues and RFB chemistries, therefore issues of system integration and components are not examined in depth, although they can be critically important for system commercialization. Before discussing the various RFB chemistries, it is worthwhile to examine their current major applications.

\subsection{Grid-storage needs}

The present electric grid constitutes an enormous physical infrastructure, with a near-instantaneous transmission of value from primary power sources and generation assets to end users and with almost no storage capability. Because of this dearth of storage, the existing grid must conform to fluctuations in customer demand, resulting in the construction of power plants that may only operate for $100 \mathrm{~h}$ a year or less and can account for up to $30 \mathrm{MWh}$ in capacity [9]. These generators are dispatched to respond to small oscillations in demand over very short time scales of 
Fig. 1 A schematic diagram of a redox flow battery with electron transport in the circuit, ion transport in the electrolyte and across the membrane, active species crossover, and mass transport in the electrolyte

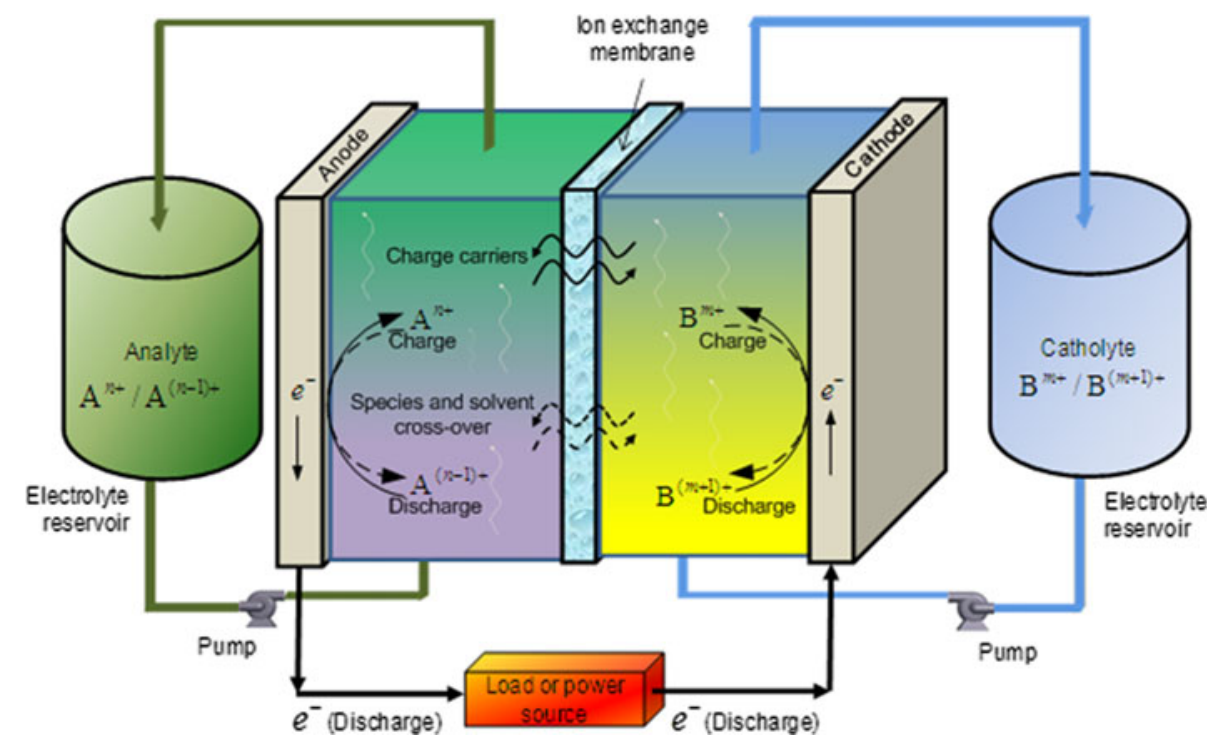

less than $1 \mathrm{~h}$. They are also turned on and sped up to meet increasing load during the peak time of the day, and, at the other extreme of wastefulness, brought on by the lack of storage. For example, wind energy is wasted because of the inability to dispatch wind power at night when wind generation is at a maximum but customer demand is at a minimum; thus, there is a significant value added by the incorporation of storage [10]. Similarly, photovoltaics and solar-energy implementation will also require arbitrage since although the solar irradiation received terrestrially in about $1 \mathrm{~h}$ is sufficient to meet worldwide energy requirements for a year, the sun does set daily. Storage is a vital tool that would uncouple customer demand from the generation side of the grid, thereby allowing vital flexibility in control and maintenance of the electric grid. To date, however, energy storage comprises only about $2 \%$ of the installed generation capacity in the U.S. Because of differences in government policy and more favorable economics, storage plays a larger role in Europe and Japan, at 10 and $15 \%$, respectively [11].

The current worldwide electric generation capacity was estimated to be about 20 trillion kilowatt hours in 2007 [12]. More than two-thirds of the current mix is from some form of fossil fuel, with most of the balance coming from nuclear and hydroelectric power generation; at present, only about $3 \%$ comes from renewable-energy technologies. Furthermore, developing economies and electrification of the transportation sector both point to strong year-over-year growth in terms of electrical demand. While coal is already the primary source of power in the US electricity sector, there are concerns that it will become a larger portion of electricity production as increased global demand competes for cleaner resources like natural gas. Coal is, of course, the most carbon-intensive resource used in this sector; however, while debate continues about how to address anthropogenic global warming gas emissions from a policy standpoint, coal plants are less capable of handling transient loads than the "peaker" plants that largely sit idle and which are deployed only to handle the peak loads. Growing demand implies not only an increase in the base load, which might be handled by coal if government and the energy sector choose not to prioritize carbon-emissions reductions, but also to larger peak loads, which will either require more intermittent generation assets or storage.

In addition to improvements in resiliency that can enable increased renewable-energy generation, integration of storage into the smart grid also promises to enable greater system efficiency, even with existing generation assets. The Electric Power Research Institute has completed a study that suggests that the widespread adoption of smart grid technologies could yield a $4 \%$ reduction in energy use by 2030 [13], roughly equivalent to eliminating the emissions of 50 million cars. Beyond the emissions impact, that savings translates to more than $\$ 20$ billion annually for utility customers nationwide. With a more robust and efficient system, and more data about demand patterns, it will be easier for utilities to manage the integration of intermittent renewable-energy sources. Energy storage can also support requirements for reserve generation in place of fossil-fuel-based facilities, yielding zero emissions and lowered operating costs.

It seems apparent that being able to harvest energy from more diverse sources, and being able to deploy this energy to the end user when it is demanded, should lower operating costs and promote the robustness and quality of power on the grid. Why then, is the penetration of storage onto the grid so small? The answer is primarily cost. There are multiple costs associated with the installation and operation of a RFB system: one must consider the operation and maintenance costs, as well as up-front capital costs 
and life-cycle costs. Because of the decoupling of energy and power in RFB configurations, we can consider both cost per unit of power generation/storage capability $(\$ / \mathrm{kW})$ and the cost per unit of energy-storage capacity $(\$ / \mathrm{kWh})$. We note that the cost per unit energy storage is not the incremental cost of producing or storing that energy as would be expected in a utility bill, but the cost per unit of energy-storage capacity. In addition to costs, robust system lifetimes of $\sim 10$ years, high efficiency, and cyclic durability are necessary for grid-level storage.

Different applications have different acceptable costs, and the total power and total duration of storage provided will differ from application to application. As such, it is difficult to target a single metric that can concisely address the ultimate cost target for grid-based storage. Table 1 below, from a report prepared by the Nexight Group based upon a workshop convened by Sandia, PNNL, and the Minerals, Metals, and Materials Society (TMS) for the US Department of Energy, suggests the following cost performance targets for key utility applications, and identify cost targets for flow batteries of $\$ 250 / \mathrm{kWh}$ in capital costs in 2015 , decreasing to $\$ 100 / \mathrm{kWh}$ by 2030 [14]. Current estimates of costs for conventional batteries and flow batteries are significantly higher than the required targets: a 2008 estimate of RFB costs suggested nearly $\$ 2500 / \mathrm{kW}$, albeit without specification of duration or sizing [15]. Regardless of detail, however, significant cost reduction must be achieved: technological improvements, material development, and economies of scale must be achieved to ensure success in the marketplace.

\section{Redox-flow-battery overview}

Redox flow batteries can be classified by active species or solvent (aqueous and non-aqueous, respectively). Figure 1 shows a generic RFB system. In the discharge mode, an anolyte solution flows through a porous electrode and reacts to generate electrons, which flow through the external circuit. The charge-carrying species are then transported to a separator (typically an ion-exchange membrane (IEM)), which serves to separate the anolyte and catholyte solutions. The general reactions can be written as

$$
\begin{aligned}
& \mathrm{A}^{n+}+x e^{-} \stackrel{\text { charge }}{\longrightarrow} \mathrm{A}^{(n-x)+} \text { and } \mathrm{A}^{(n-x)+} \stackrel{\text { discharge }}{\longrightarrow} \mathrm{A}^{n+}+x e^{-} \\
& (n>x)
\end{aligned}
$$

and

\begin{tabular}{|c|c|c|}
\hline Application & Purpose & Key performance targets \\
\hline $\begin{array}{l}\text { Area and frequency regulation } \\
\text { (short duration) }\end{array}$ & $\begin{array}{l}\text { Reconciles momentary differences between } \\
\text { supply and demand within a given area }\end{array}$ & $\begin{array}{l}\text { Service cost: } \$ 20 / \mathrm{MW} \\
\text { Roundtrip efficiency: } 85-90 \% \\
\text { System lifetime: } 10 \text { years } \\
\text { Discharge duration: } 15 \text { min-2 h } \\
\text { Response time: milliseconds }\end{array}$ \\
\hline $\begin{array}{l}\text { Renewables grid integration } \\
\text { (short duration) }\end{array}$ & $\begin{array}{l}\text { Offsets fluctuations of short-duration } \\
\text { variation of renewables generation output } \\
\text { Accommodates renewables generation at } \\
\text { times of high grid congestion }\end{array}$ & $\begin{array}{l}\text { Roundtrip efficiency: } 90 \% \\
\text { Cycle life: } 10 \text { years } \\
\text { Capacity: } 1-20 \mathrm{MW} \\
\text { Response time: } 1-2 \mathrm{~s}\end{array}$ \\
\hline $\begin{array}{l}\text { Transmission and distribution } \\
\text { upgrade deferral (long } \\
\text { duration) }\end{array}$ & $\begin{array}{l}\text { Delays or avoids the need to upgrade } \\
\text { transmission and/or distribution } \\
\text { infrastructure } \\
\text { Reduces loading on existing equipment to } \\
\text { extend equipment life }\end{array}$ & $\begin{array}{l}\text { Cost: } \$ 500 / \mathrm{kWh} \\
\text { Discharge duration: } 2-4 \mathrm{~h} \\
\text { Capacity: } 1-100 \mathrm{MW} \\
\text { Reliability: } 99.9 \% \\
\text { System life: } 10 \text { years }\end{array}$ \\
\hline Load following (long duration) & $\begin{array}{l}\text { Changes power output in response to the } \\
\text { changing balance between energy supply } \\
\text { and demand } \\
\text { Operates at partial load (i.e., increased } \\
\text { output) without compromising performance } \\
\text { or increasing emissions }\end{array}$ & $\begin{array}{l}\text { Capital cost: } \$ 1,500 / \mathrm{kW} \text { or } \$ 500 / \mathrm{kWh} \\
\text { Operations and maintenance cost: } \$ 500 / \mathrm{kWh} \\
\text { Discharge duration: } 2-6 \mathrm{~h}\end{array}$ \\
\hline $\begin{array}{l}\text { Electric energy time shift (long } \\
\text { duration) }\end{array}$ & $\begin{array}{l}\text { Stores inexpensive energy during low } \\
\text { demand periods and discharges the energy } \\
\text { during times of high demand (often referred } \\
\text { to as arbitrage) }\end{array}$ & $\begin{array}{l}\text { Capital cost: } \$ 1,500 / \mathrm{kW} \text { or } \$ 500 / \mathrm{kWh} \\
\text { Operations and maintenance cost: } \$ 250-\$ 500 / \mathrm{kWh} \\
\text { Discharge duration: } 2-6 \mathrm{~h} \\
\text { Efficiency: } 70-80 \% \\
\text { Response time: } 5-30 \mathrm{~min}\end{array}$ \\
\hline
\end{tabular}

Table 1 Key performance targets for grid-storage applications, from Ref. [14] 
$\mathrm{B}^{m+}-y e^{-\stackrel{\text { charge }}{\longrightarrow}} \mathrm{B}^{(m+y)+}$ and $\mathrm{B}^{(m+y)+} \stackrel{\text { discharge }}{\longrightarrow} \mathrm{B}^{m+}-y e^{-}$

for the anode (negative electrode) and cathode (positive electrode), respectively.

The key transport mechanisms are shown in Fig. 1 for this generic system. The dominant losses in these systems, other than charge-transfer reaction kinetics, are related to the charge and mass transport in the electrolyte and separator, which are each discussed in turn in later sections of this review. Additionally, a key factor in many of these systems is crossover of species through the separator, which is dependent on current and membrane permeability. A sample RFB cell performance is shown in Fig. 2, where the charge and discharge are at different rates or current densities. One can see that similar to a fuel-cell polarization curve, there can be ohmic, mass-transport, and/or kinetic losses. The first part of the curves is dominated by kinetic overpotential, especially on charge. The middle part of the curves is dominated by ohmic or ionic-conduction losses, and the last part of the curves is typically a signature of reactant mass-transport limitations.

The reactor in Fig. 1 consists of a stack of individual cells, where each cell contains the sites where electrochemical charge-transfer reactions occur as electrolyte flows through them, as well as a separator (either an electrolyte-filled gap or a selective membrane) to force the electrons through the external circuit. The arrangement of a typical cell is shown in Fig. 3, and individual cells can be arranged in series to increase the overall stack voltage. Generally, stacks are arranged in a bipolar fashion so that current flows in series from one cell to the next.

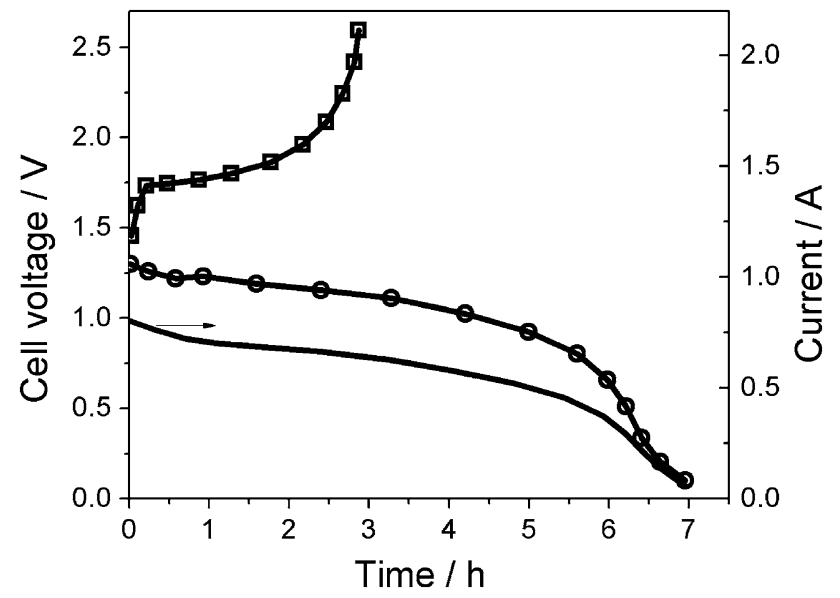

Fig. 2 Charge-discharge curves of an all vanadium RFB using $0.5 \mathrm{M}$ $\mathrm{VOSO}_{4}$ in $2 \mathrm{M} \mathrm{H}_{2} \mathrm{SO}_{4}$ and sulfonated polyethylene membrane. Electrode area $=90 \mathrm{~cm}^{2}$; charging current density $=15 \mathrm{~mA} \mathrm{~cm}{ }^{-2}$; The discharge process used a $1 \Omega$ resistor and the average discharge current density $=6 \mathrm{~mA} \mathrm{~cm}^{-2}$. Adapted from Ref. [16] with permission

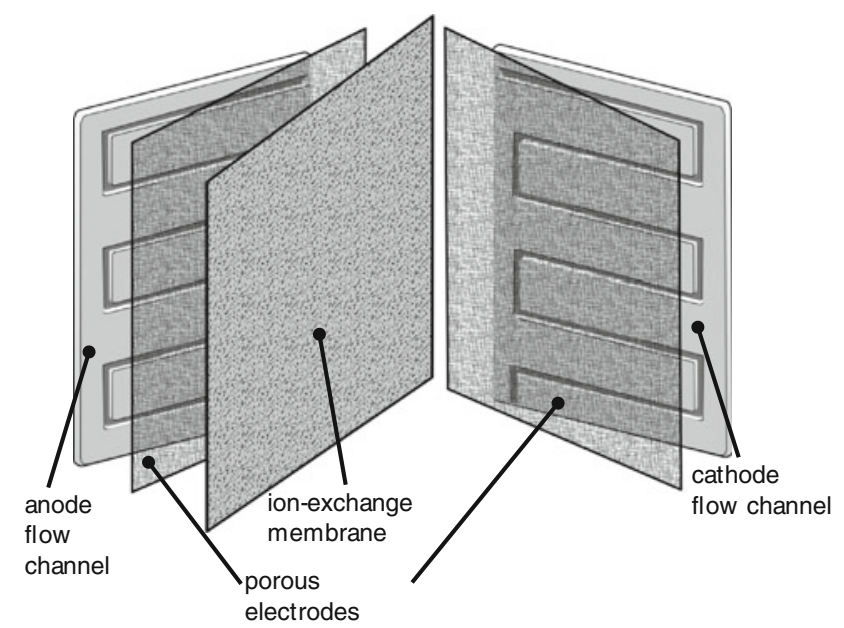

Fig. 3 Schematic diagram of standard RFB cell construction

One of the key attributes of RFBs that suggests significant promise for stationary applications is the fact that, for many configurations, there is no physical transfer of material across the electrode/electrolyte interface. While there are some configurations that can be categorized as flow batteries only in the sense that the active material flows from outside of the cell to the electrode surface, most flow-battery systems under development utilize reversible solution-phase electrochemical couples on two electrodes to store chemical energy. Instead of storing the electrochemical reactants within the electrode itself, as with metal/metal alloy or intercalation electrodes, the reactants are dissolved in electrolytic solutions and stored in external tanks. Both the oxidized and reduced form of each reactant are soluble in the electrolyte, so they can be carried to/from the electrode surface in the same phase. Only the relative concentrations of oxidized and reduced forms change in each stream over the course of charge and discharge.

The electrodes in most RFB configurations are not required to undergo physical changes such as phase change or insertion/deinsertion during operation because the changes are occurring in the dissolved reactants in the solution phase adjacent to the solid-electrode surfaces. Though there are exceptions to this formulation, as mentioned in the next section, this feature generally affords the opportunity to simplify the electrode design considerably. As a consequence of the charge-transfer characteristics, the cycle life of a RFB is not directly influenced by depth-ofdischarge or number of cycles the way that conventional rechargeable batteries are. Side reactions can, of course, complicate design and operation, but if the reactions proceed as intended, degradation of the electrode surface need not proceed as a matter of course. The decoupling of storage and reaction in RFB systems is an advantage in terms of flexibility, but it complicates their designs relative 
to conventional batteries, and adds a mechanical balanceof-plant element for pumping the often highly corrosive liquid electrolyte; as a result, their specific mass and volumetric energy densities are much lower than conventional batteries. A RFB configuration can nevertheless exceed the performance of other grid-storage technologies and does not require specific geographical siting, as pumped hydroelectric and compressed-air energy storage (CAES) do.

Additionally, RFBs offer the important advantage that power and energy outputs are independent variables since the power is determined by the reactor size and the amount of energy stored depends on the reactants chosen, their concentration, and the size of the reactant tanks [16-18]. The amount of energy that can be stored in a conventional sealed battery is generally limited by the effective path lengths for diffusion and migration in the direction normal to the current collector; making an electrode thicker will add to the amount of active material, but one experiences diminishing returns in terms of energy extraction because of diffusional and ohmic losses in these systems.

As shown in Fig. 1, most RFB systems currently require two separate electrolyte tanks: one for the anolyte and another for the catholyte. This ensures that the potentials at each electrode are close to the reversible potential for each of the half-cell reactions, and side reactions or competition from the other half-cell reactions are minimized. This does, however, add to the size and cost of the system, and it also requires a uniform delivery of the dissolved species to the entire surface area as oftentimes most of the convective flow is parallel to the electrode surface rather than being flowed directly through it. Details of ion transport and flow configurations are discussed more thoroughly in a subsequent section.

The key costs of RFBs are the active material stored in the electrolyte and the electrochemical cell itself. The construction costs of the cell scale with the total power requirement of the application, but these costs are directly rated to the specific power of the device itself, i.e., how effectively the materials are utilized. While RFBs ought to be able to operate at relatively high current densities, as convection can be employed to deliver reactants to the electrode surface, RFBs have typically been operated at current densities consistent with conventional batteries without convection. It is anticipated that electrolyte management and cell design can deliver significant improvements in power density, thereby reducing considerably cell material costs.

\subsection{Redox-flow-battery chemistries}

Several battery technologies have been considered for gridbased storage in recent decades. Traditional rechargeable batteries have been modified and optimized for grid-based storage and are being deployed in some installations, including lead-acid, nickel-based, and lithium-ion batteries; but we turn our attention to RFBs, which have been demonstrated on the order of $100 \mathrm{~kW}$ to $10 \mathrm{MW}$. RFBs are generally categorized based upon the anolyte and catholyte that comprise the form of energy storage of the system. Figure 4 shows some basic redox couples, charge-transfer, and ion-carrier-migration modes in various specific RFBs. As shown in Fig. 4, configurations with the same species but different oxidation states (such as all-vanadium) as well as different active species in the anolyte and catholyte are used. In this section, we introduce the various important RFB types and briefly some of the advantages, disadvantages, and challenges of each.

\subsubsection{Iron/chromium}

Modern development of what we might term a RFB began with the development of an iron/chromium system $(\mathrm{Fe} / \mathrm{Cr})$ in the 1970s at NASA, which demonstrated a $1 \mathrm{~kW} /$ $13 \mathrm{kWh}$ system for a photovoltaic-array application [19, 20]. The Fe/Cr system is based upon an aqueous solution of a ferric/ferrous redox couple at the positive electrode $\left(\mathrm{Fe}^{2+} / \mathrm{Fe}^{3+}\right)$; the negative electrolyte is a mixture of chromic and chromous ions $\left(\mathrm{Cr}^{2+} / \mathrm{Cr}^{3+}\right)$; most systems use hydrochloric acid as the supporting electrolyte. The chargetransfer reactions at each electrode are

$\mathrm{Fe}^{2+} \leftrightharpoons \mathrm{Fe}^{3+}+e^{-}, \quad E^{0}=0.77 \mathrm{~V}$ vs. RHE

and

$\mathrm{Cr}^{2+} \leftrightharpoons \mathrm{Cr}^{3+}+e^{-}, \quad E^{0}=-0.41 \mathrm{~V}$ vs. RHE

The system can operate with an IEM/separator and lowcost carbon-felt electrodes. Both charge-transfer reactions require only a single-electron transfer, which is expected to simplify charge transfer and result in reasonable surface overpotentials without specific electrocatalysts. Indeed, the iron redox couple is highly reversible on carbon or graphite electrodes, but the chromium redox couple has significantly slower kinetics and does require electrocatalysts. This system has a relatively low open-circuit potential (between 0.90 and $1.20 \mathrm{~V}$ ), and designers must endure crossover of iron to the chromium stream and vice versa. Some Japanese companies built similar batteries by licensing the NASA patents, but have not shown improvement in the low output voltage and efficiency [21].

\subsubsection{Bromine/polysulfide}

The bromine/polysulphide RFB was patented by Remick [17] then extensively studied by Regenesys Technology 
Fig. 4 Schematic of charge transport in various redox-flow systems (the values give the potential of the redox couple). a All vanadium, b vanadium/ bromine, $\mathbf{c}$ iron/chromium, d Fe-EDTA/bromine, e zinc/ cerium, f bromine/polysulphide, g nonaqueous ruthenium/ bipyridine, $\mathbf{h}$ nonaqueous vanadium/acetylacetonate, i nonaqueous chromium/ acetylacetonate
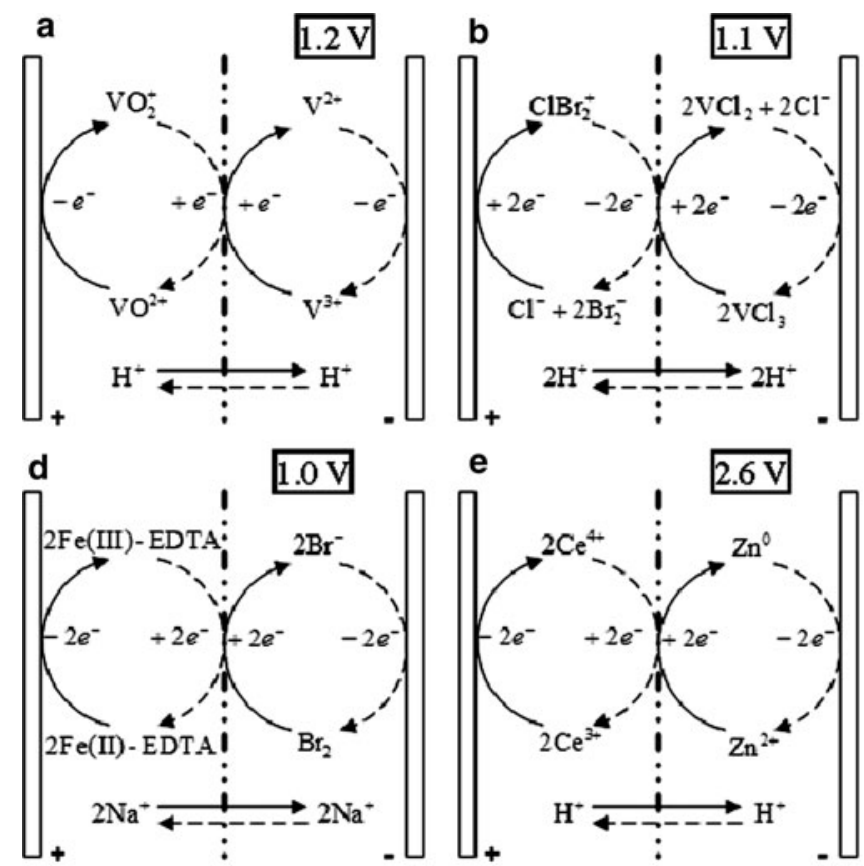

C

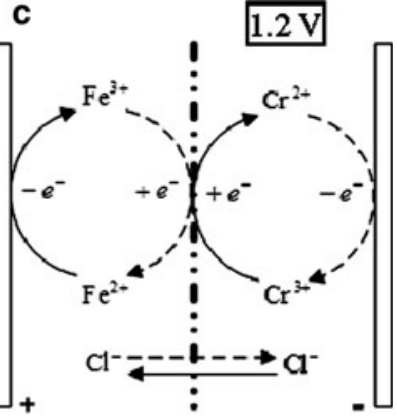

e $2.6 \mathrm{~V}$

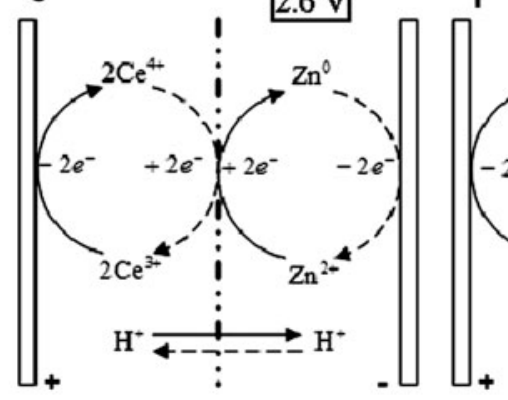

f
$1.5 \mathrm{~V}$
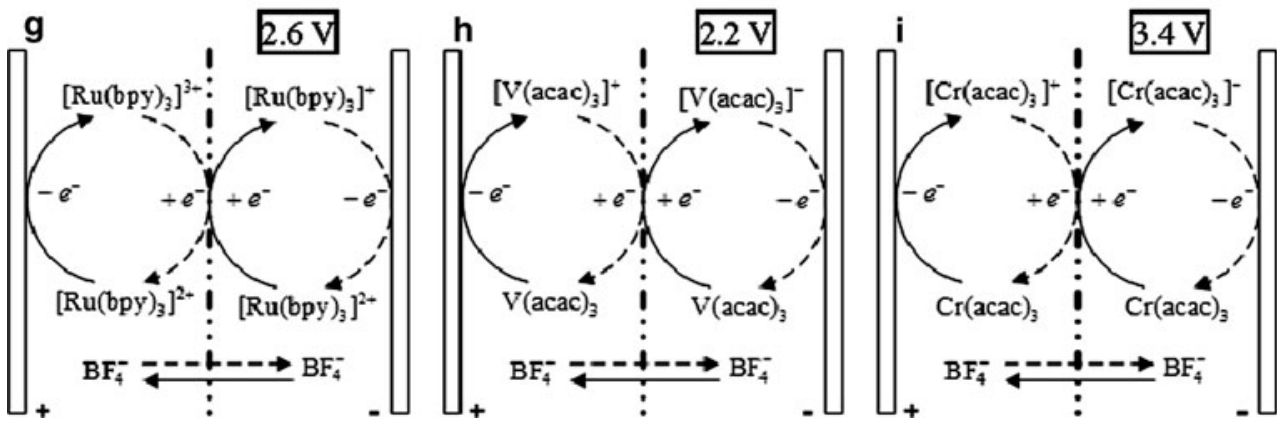

$2 \mathrm{~S}_{2}{ }^{2-} \leftrightharpoons \mathrm{S}_{4}{ }^{2-}+2 e^{-}, \quad E^{0}=-0.265 \mathrm{~V}$ vs. RHE

[22] from 1993 until 2006 when it was acquired by VRB Power Systems [5]. To date, three series of bromine/ polysulphide RFB systems have been developed, including 5,20 , and $100 \mathrm{~kW}$ class systems. A commercial-size 15 MW system was successfully demonstrated. This plant used up to 120 modules, and 200 bipolar electrodes with an energy storage capacity up to $12 \mathrm{MWh}$ and two $1800 \mathrm{~m}^{3}$ electrolyte storage tanks [23].

In the bromine/polysulfide system, the positive electrolyte is sodium bromide, and the negative electrolyte is sodium polysulfide, though, the counter-ion could be replaced with another cation. The key attributes of this system are that the species that comprise the two electrolytes are abundant and reasonably inexpensive; furthermore, they are highly soluble in aqueous electrolytes, which reduces the volume of electrolyte that is required to store a given quantity of charge. At the positive electrode, three bromide ions combine to form the tribromide ion

$3 \mathrm{Br}^{-} \leftrightharpoons \mathrm{Br}_{3}{ }^{-}+2 e^{-}, \quad E^{0}=1.09 \mathrm{~V}$ vs. RHE

At the negative electrode, the sulfur in solution is shuttled between polysulfide and sulfide
In this system, all of the electroactive species are anions, so a cation-exchange membrane is needed to prevent mixing of the anolyte and catholyte streams. Charge is carried via sodium ions through the membrane. When activated carbon/polyolefin composite electrodes were used in this system, the voltage increased from 1.7 to $2.1 \mathrm{~V}$ during the charging process due to adsorption of bromine in the activated carbon [24]. This system is prone to crossover and mixing of the electrolytes, however, which can lead to precipitation of sulfur species and the formation of $\mathrm{H}_{2} \mathrm{~S}$ and $\mathrm{Br}_{2}$.

\subsubsection{All-vanadium}

In both of the systems described above, a chief concern and liability is the incompatibility between, and sensitivity of, the two electrolyte streams to contamination from the other. If a species crosses over and reacts irreversibly with elements in the opposite stream, it comprises not just an efficiency loss on that particular charge/discharge cycle, 
but a loss of capacity and degradation in the overall performance of the system, which may result in expensive electrolyte separation and reactant recovery. To this end, it is helpful to develop a system with more than two oxidation states of the same element, wherein crossover only represents an efficiency loss as no species are irreversibly consumed or removed from their reactive electrolytic solution. The all-vanadium system employs the V(II)/ $\mathrm{V}$ (III) redox couple at the negative electrode and the $\mathrm{V}(\mathrm{IV}) / \mathrm{V}(\mathrm{V})$ redox couple at the positive electrode, generally identified to exist in the form of $\mathrm{VO}^{2+}$ and $\mathrm{VO}_{2}{ }^{+}$

$$
\begin{aligned}
& \mathrm{V}^{2+} \leftrightharpoons \mathrm{V}^{3+}+e^{-}, \quad E^{0}=-0.26 \mathrm{~V} \text { vs. RHE } \\
& \mathrm{VO}^{2+}+\mathrm{H}_{2} \mathrm{O} \leftrightharpoons \mathrm{VO}_{2}^{+}+2 \mathrm{H}^{+}+e^{-} \\
& E^{0}=1.00 \mathrm{~V} \text { vs. RHE }
\end{aligned}
$$

In this case, the current is maintained by the migration of protons across the membrane separator. While it is nominally the change in the oxidation state of vanadium on either side of the membrane that stores and releases charge, there is a change in the $\mathrm{pH}$ of the solution over the course of a charge and discharge cycle. While crossover of the different oxidation states of vanadium comprises an efficiency loss, the proper forms can be regenerated electrochemically, which eases the stringency of maintenance requirements.

While exploratory research on vanadium as a redox couple began at NASA [8], the all-vanadium redox battery (VRB) was invented and developed by Maria SkyllasKazacos and her co-workers at the University of New South Wales [16, 25, 26]. Research has continued on this technology since that time. As a promising technology for storing intermittent renewable energy, VRB systems have received perhaps the most attention of all RFBs [16, 2739]. In fact, prototypes up to the range of MW in power and MWh in energy-storage capacity have been demonstrated [3, 35, 40-47]. Figure 5 shows the 5-10 kW VRB stack developed by Skyllas-Kazacos' group along with its general efficiencies.

While energy density is not necessarily a primary concern for stationary, grid applications, nonetheless, the VRB energy density is limited by the solubility of vanadium in the electrolyte stream and precipitation can occur; the solubility limits depend upon both acid concentration and temperature [49].

\subsubsection{Vanadium/bromine}

Because there are limits to how much vanadium can be stored in solution in the VRB system, some of the same researchers who pioneered the work on the VRB cell noted that vanadium solubility could be boosted in the presence of halide ions. In this case, during charging the bromide ions in the positive half-cell undergo oxidation to what is assumed to be the polyhalide ion $\mathrm{Br}_{2} \mathrm{Cl}^{-}$; the formal potential of this couple is about $1.3 \mathrm{~V}$ more positive than the $\mathrm{V}(\mathrm{II}) / \mathrm{V}(\mathrm{III})$ couple $[48,50,51]$. The researchers were able to show significantly higher solubilities in this system: vanadium-bromide solutions with nearly twice the solubility on a molar basis relative to vanadium sulfate solutions were demonstrated. The higher solubility of vanadium bromine results in higher energy densities (35-70 Wh/L) compared to the VRB systems $(25-35 \mathrm{Wh} /$ L). However, the potential concern of vanadium/bromine redox systems is toxic bromine-vapor emissions during operation, and thus Skyllas-Kazacos also used bromine complexing agents including tetrabutylammonium bromine, polyethylene glycol, $N$-methyl- $N$-ethyl morpholinium bromide, and $N$-methyl- $N$-ethyl pyrrolidinium bromide to decrease or eliminate bromine-vapor emissions during operation [38]. Shown in Fig. 6 is a typical series of charge-discharge curves using a charge-discharge current density of $20 \mathrm{~mA} / \mathrm{cm}^{2}$ [48]. Generally, the coulombic efficiency increases with increasing current density due to lower self-discharge through the membrane; however, it decreases as temperature increases due to more rapid diffusion of vanadium and polybromide ions through the membrane.

\subsubsection{Hydrogen-based systems}

A fuel cell takes a fuel (normally hydrogen) and an oxidant (typically air) and produces electricity and water. For a fuel
Fig. 5 a $5-10 \mathrm{~kW}$ VRB stack. b Stack efficiencies and capacity versus stack discharge current. Adapted from Ref. [48] with permission
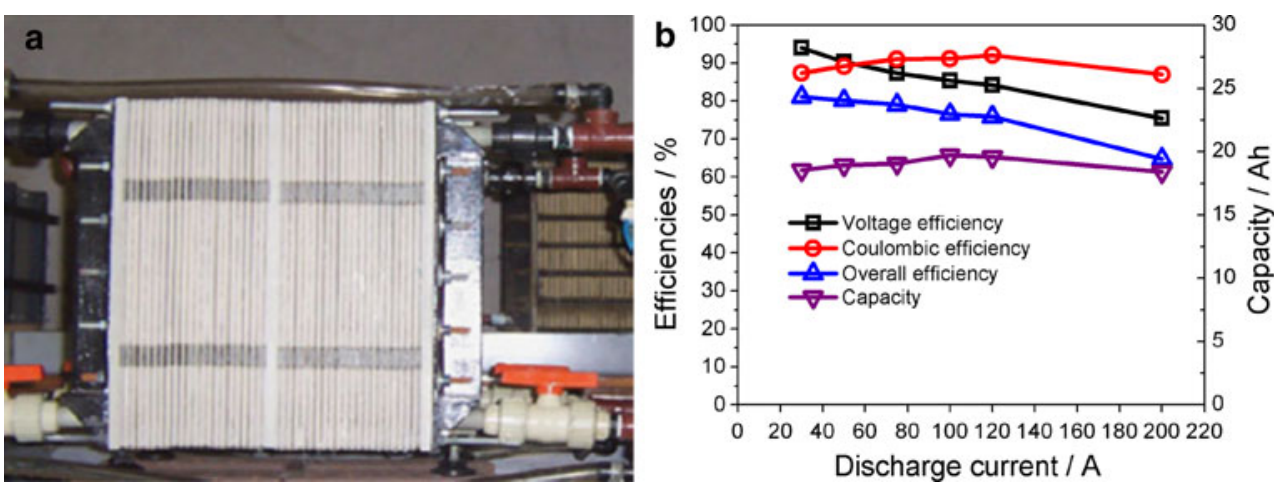


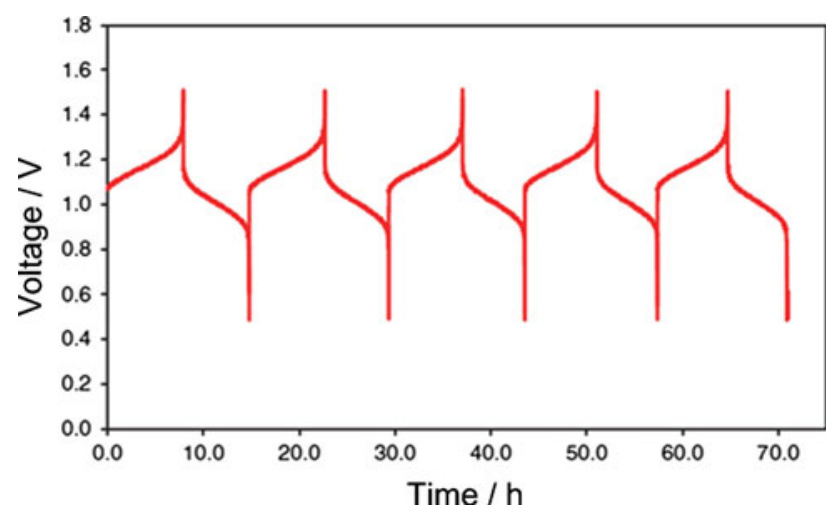

Fig. 6 A series of charge-discharge curves for vanadium-bromine redox cells using $2.5 \mathrm{M}$ vanadium bromide electrolyte with the charge-discharge current density $=20 \mathrm{~mA} \mathrm{~cm}^{-2}$ and $T=30^{\circ} \mathrm{C}$. Adapted from Ref. [48] with permission. These curves do not correspond to the same stack operating conditions as shown in Fig. 5

cell, hydrogen oxidizes at the anode according to the reaction

$\mathrm{H}_{2} \rightarrow 2 \mathrm{H}^{+}+2 e^{-}, \quad E^{0}=0 \mathrm{~V}$ vs. RHE

and, at the cathode, oxygen is reduced

$4 \mathrm{H}^{+}+4 e^{-}+\mathrm{O}_{2} \rightarrow 2 \mathrm{H}_{2} \mathrm{O}, \quad E^{0}=1.229 \mathrm{~V}$ vs. RHE

If one were to design a system where the fuel cell acts in both the charge and discharge directions (i.e., a reversible or regenerative fuel cell), then a RFB system would exist. Such a RFB system has been examined both with the same and different stacks for charge and discharge [52-55]. This system is inherently different from the RFBs discussed above since the reactants are in the gas and not liquid phase, which enhances mass transfer at the expense of storage tank volume, and thus hydrogen compression or novel hydrogen-storage materials are needed. Although mass transfer is typically rapid, the oxygen reactions are known to be very sluggish and result in very large overpotentials [56], thereby rendering the overall efficiency of the system to be relatively low. To enhance as well as drive down the cost of the hydrogen/oxygen system, strategies including looking at alkaline media, high temperatures, and closed systems with oxygen and not air. Also, because of the difficulty associated with finding robust and effective oxygen reduction/evolution catalysts, different oxidants have been examined including bromine and chlorine, both of which react rapidly on carbon surfaces [57-59].

\subsubsection{Hybrid redox-flow batteries}

There are other battery configurations that share a development heritage and some common issues with what we would classify as RFBs in that the active material can be introduced to, or removed from, the electrochemical cell without disassembling the cell structure, but which do not store all of the active material in a liquid or gaseous form per se. As such, we might consider them semi-flow cells with electrochemical reactions that are more complicated than simply shuttling between the oxidation states of a single species.

2.1.6.1 Zinc/bromine The prototypical hybrid or semiflow RFB is the zinc/bromine system [60]. In this system, electrolyte solutions containing the reactive species are stored in external tanks and circulated through each cell in the stack, but the zinc reaction does not only involve dissolved species in the aqueous phase. At the positive electrode, bromide ions are transformed to bromine and back, see Eq. 5. It is important to note that the bromide ions can combine with bromine molecules to generate the tribromide ion [61]

$\mathrm{Br}_{2}+\mathrm{Br}^{-} \leftrightharpoons \mathrm{Br}_{3}{ }^{-}$

which occurs primarily in liquid bromine. In this system, relatively high concentrations of $\mathrm{Br}^{-}$and $\mathrm{Br}_{2}$ can be utilized, enhancing both reaction kinetics and energy density. The toxicity of $\mathrm{Br}_{2}$ and the highly complexing/corroding character of concentrated $\mathrm{HBr}$ are limitations however. The toxicity of $\mathrm{Br}_{2}$ can be mitigated by the use of complexing agents [62], but the effect of complexing agents on kinetics has not been studied quantitatively, particularly in strongly acidic supporting electrolyte.

At the negative electrode, zinc metal is dissolved and redeposited,

$\mathrm{Zn} \leftrightharpoons \mathrm{Zn}^{2+}+2 e^{-}, \quad E^{0}=-0.76 \mathrm{~V}$ vs. RHE

To prevent self-discharge by combination of zinc and bromine, separate flowing streams of aqueous zinc bromide and bromine circulate in separate loops, separated by an IEM or a microporous film [63].

The metal negative electrode allows for a compact electrode, thus increasing the energy density. In addition, the zinc/bromine system has a high cell voltage, good reversibility, and expectations of low material costs. However, the demonstration of zinc/bromine has been limited due to material corrosion, dendrite formation and electrical shorting, high self-discharge rates, low energy efficiencies, and short cycle life. RedFlow Ltd. successfully demonstrated a zinc/bromine RFB unit up to MW size with an energy efficiency of nearly $74 \%$ in Australia [64]. The cell architecture was designed to optimize plating and deplating efficiency of zinc during charging and discharging operations. Derivatives of the zinc/bromine system include other halogens such as zinc/chlorine, which typically have similar performance and issues [65].

2.1.6.2 Soluble lead acid A soluble form of the lead-acid battery has also been considered [9]. The charge-transfer 
reactions as written are the same as in a traditional sealed lead-acid battery configuration. Lead-acid batteries do not shuttle the same ion between the negative and positive electrode; that is, $\mathrm{Pb}^{2+}$ is introduced and removed from solution at the negative electrode as lead is dissolved and plated,

$\mathrm{Pb} \leftrightharpoons \mathrm{Pb}^{2+}+2 e^{-}, \quad E^{0}=-0.13 \mathrm{~V}$ vs. RHE

but at the positive electrode, lead ions combine with water to produce lead dioxide and protons,

$$
\begin{aligned}
\mathrm{Pb}^{2+} & +2 \mathrm{H}_{2} \mathrm{O} \leftrightharpoons \mathrm{PbO}_{2}+4 \mathrm{H}^{+}+2 e^{-}, \\
E^{0} & =1.49 \text { V vs. RHE }
\end{aligned}
$$

As lead ions are produced in the oxidation step at the negative electrode and produced in the reduction step at the positive electrode on discharge, there is not a risk of crossover lowering the overall efficiency of the system. As long as the solid forms of lead and lead dioxide are maintained at the negative and positive electrodes, circulation of electrolyte can maintain the open-circuit potential of the battery and allow greater specific cell performance than with sealed or flooded lead-acid cells, assuming minimal weight and volume of the external storage tank. As with other semi-solid flow configurations, there are risks associated with maintaining the morphology of the solid phase as material can detach or grow across the separator gap to cause short-circuit problems.

2.1.6.3 All iron Similar to the all-vanadium RFB, the all-iron system [66, 67] involves only a single element, where on one electrode iron(II) goes to iron(III), Eq. 3, and on the other plating of iron occurs

$\mathrm{Fe} \leftrightharpoons \mathrm{Fe}^{2+}+2 e^{-}, \quad E^{0}=-0.3 \mathrm{~V}$ vs. RHE

Due to the single species, crossover is not as much a concern although it is still a current inefficiency. This system has some of the same issues as the other hybrid batteries including getting uniform plating of the metal, thereby necessitating precise $\mathrm{pH}$ control and supporting electrolyte; however, iron does not have the extensive dendrite problems of zinc. The benefits of the cell are also that the materials are nonhazardous and inexpensive. These are balanced by the fact that the overall cell voltage is relatively low and hydrogen generation can occur, although iron is a poor hydrogen-evolution catalyst.

\subsubsection{Non-aqueous redox-flow batteries}

The use of non-aqueous electrolytes in RFB configurations has been considered because of the higher cell potentials that are possible when one is not concerned by the breakdown of the aqueous electrolyte. In addition, many couples and reactants are much more soluble in non-aqueous solvents. However, the challenges of low electrolyte conductivities, stability, and cost limit the development of nonaqueous RFB systems.

As an example, the zinc/cerium cell has been worked on by Plurion Limited. As with the zinc/bromine cell, the negative electrode dissolves and plates zinc, Eq. 12, and at the positive electrode, cerium is shuttled between $\mathrm{Ce}$ (III) and $\mathrm{Ce}(\mathrm{IV})$

$\mathrm{Ce}^{3+} \leftrightharpoons \mathrm{Ce}^{4+}+e^{-}, \quad E^{0}=1.75 \mathrm{~V}$ vs. RHE

The developers claim a cell potential of approximately $2.5 \mathrm{~V}$ on charging, but it drops below $2 \mathrm{~V}$ during discharge with an energy density of 37.5 to $120 \mathrm{Wh} / \mathrm{L}$ [68, 69]. The high operating potential window is achieved by using methane sulfonic acid rather than pure water as the solvent, thus minimizing decomposition of water into hydrogen and oxygen, as well as aiding in zinc plating. The redox reaction of $\mathrm{Ce}(\mathrm{III}) / \mathrm{Ce}(\mathrm{IV})$ is kinetically slow and $\mathrm{Ce}(\mathrm{III})$ has a somewhat low diffusivity [70, 71]. High acid strength facilitates the solubility of $\mathrm{Ce}(\mathrm{IV})$; however, the solubility of $\mathrm{Ce}$ (III) decreases at higher acid concentrations. Other electrochemical couples including zinc/chlorine [72], zinc/ ferricyanide [69], and vanadium/cerium [73] have been considered. While non-aqueous electrolytes generally imply higher costs than aqueous electrolytes and must be vetted for environmental and chemical compatibility, the expansion of the operating potential window is attractive, as the cell potential difference has a direct impact on the amount of power that can be delivered for a specified current density.

Other examples of nonaqueous RFBs include that of Matsuda et al. [74] who demonstrated a redox system based on $\left[\mathrm{Ru}(\mathrm{bpy})_{3}\right]^{2+} /\left[\mathrm{Ru}(\mathrm{bpy})_{3}\right]^{3+}$ (bpy is bipyridine) as the anolyte and $\left[\mathrm{Ru}(\mathrm{bpy})_{3}\right]^{+} /\left[\mathrm{Ru}(\mathrm{bpy})_{3}\right]^{2+}$ as the catholyte in acetonitrile $\left(\mathrm{CH}_{3} \mathrm{CN}\right)$ with tetraethylammonium tetrafluoroborate $\left(\mathrm{TEABF}_{4}\right)$ as the supporting electrolyte. This system yielded an open-circuit potential of $2.6 \mathrm{~V}$, with an energy efficiency of $40 \%$. Chakrabarti et al. evaluated a redox system based on a ruthernium acetylacetonate, obtaining a cell potential of $1.77 \mathrm{~V}$ [75]. Yamamura et al. [76] studied a non-aqueous system which used various uranium beta-diketonates with the cell potentials of about $1 \mathrm{~V}$.

Recently, Thompson and co-workers demonstrated a redox-flow system using $\mathrm{M}(\mathrm{acac})_{3}(\mathrm{M}=\mathrm{V}, \mathrm{Cr}$ or $\mathrm{Mn}$, and acac is acetylacetonate) with at least three different oxidation states [77-79]. The vanadium and chromium acetylacetonate systems showed higher open-circuit potentials, 2.2 and $3.4 \mathrm{~V}$, respectively, compared to around $1.26 \mathrm{~V}$ for the aqueous VRB system. However, crossover and ohmic losses due to the large distances between positive and negative electrodes limited the coulombic efficiency. Although the $\mathrm{Mn}(\mathrm{acac})_{3}$ system shows a lower open-circuit potential $(1.1 \mathrm{~V})$ than that of $\mathrm{V}(\mathrm{acac})_{3}, \mathrm{Cr}(\mathrm{acac})_{3}$, and $\mathrm{VRB}$, it exhibits better reversibility both for $\mathrm{Mn}(\mathrm{II}) / \mathrm{Mn}(\mathrm{III})$ and 
$\mathrm{Mn}(\mathrm{III}) / \mathrm{Mn}(\mathrm{IV})$ redox couples, with a columbic efficiency approaching $97 \%$ in a static H-type cell. Shinkle et al. studied the degradation mechanisms in the non-aqueous $\mathrm{V}(\mathrm{acac})_{3}$ redox systems [80], and showed that environmental oxygen and water are associated with side reactions that affect the long-term charge-discharge response of the battery.

\subsubsection{Other configurations}

There is recent interest in the development of the lithiumair battery, which operates with a static lithium negative electrode, as might be found in a lithium-ion or lithiumpolymer battery. Lithium ions combine with oxygen from air to form lithium oxide at the positive electrode on discharge; oxygen is regenerated during charging. Kraytsberg and Ein-Eli provide an overview of the technology [81]. There are many challenges with such a battery system, such as ensuring proper isolation of the negative electrode from oxygen and water crossover and ensuring an electrode structure that provides for facile oxygen transport and reversible oxide formation and stripping. However, the promise for high energy density and low material costs suggest tremendous research opportunities.

Another recent flow-cell concept was invented by Yet-Ming Chiang's group at MIT and described by Duduta et al. [82, 83]. They proposed using typical intercalation electrode materials as active materials for a lithium rechargeable battery, but providing the active material in a slurry that can be mechanically pumped into and out of a reaction chamber. In the paper describing the concept, they note that they will be able to store much higher concentrations of active material in the solid component of the slurry than can be stored as ions dissolved in electrolyte (up to $24 \mathrm{M}$ ), thereby increasing the energy density well beyond what could be achieved in traditional RFBs.

\section{Kinetics of redox reactions}

The study of the kinetics of redox reactions occupies a central place in fundamental electrochemistry. Most important concepts in the theory of electrode reactions were developed from the consideration of redox reactions. The simplest form of a redox reaction is a one-electron transfer of an electron to or from an electrode to an ion in solution, written generally as

$\mathrm{O}+n e^{-} \leftrightharpoons \mathrm{R}$

where $\mathrm{O}$ is the oxidized state and $\mathrm{R}$ the reduced state of the ion. In the simplest type of redox reaction, there are no changes in the ion other than the valence state and relaxation of the solvent around the ion. The prototypical example of such a reaction is the ferrous/ferric reaction in solutions of sulfuric acid (meticulously free of chloride ion, as discussed in more detail below). The reactions become more complex, and the theory more involved, when the ions are complexed with neutral or other anions that do not participate in the electron transfer directly (i.e., it does not change valence or state of charge), but are part of the relaxation of solvating ligands or assist the transfer of the electron from the electrode surface, termed mediated electron transfer. Ferri-/ferrocyanide and ferric/ferrous chloride would be examples, respectively, of such redox couples. There are also reactions involving multi-atom ions and reactions where one state is a neutral molecule that are termed redox reactions. There are no hard criteria for what is or is not a "redox" reaction, but a common feature is that it involves electron transfer that is at least measurably reversible. For the purposes here, we will discuss only the more well-studied reactions that have some promise as RFB couples as mentioned above.

Most of the fundamental principles for the kinetics of electron transfer can be found in two classic texts in electrochemistry, and those form the basis of the principles reviewed here. The first is the text by Vetter [84], which contains an interesting and unique description of the history of the development of the fundamental theory of electrode kinetics, including the familiar names of Butler and Volmer, but less recognized (in this context) names such as Gurney, Erdey-Gruz and Vetter himself [84]. This text also reviews experimental results for more than 25 redox couples, all from original papers published before ca. 1960 , but these references remain in some cases as the best source of quantitative kinetic parameters versus more recent but qualitative (or less rigorous) measurements. Another important resource is the text by Bard and Faulkner [85], more accessible than the Vetter text, with notation and terminology that is more contemporary. Following the notation in Bard and Faulkner, the ButlerVolmer model of the kinetics of reaction produces the essential current $(i)$-overpotential $(\eta)$ relationship as

$$
\begin{aligned}
i= & i_{0}\left[\left(\frac{c_{\mathrm{O}}(0, t)}{c_{\mathrm{O}}^{*}}\right) \exp \left(\frac{\alpha F}{R T} \eta\right)\right. \\
& \left.-\left(\frac{c_{\mathrm{R}}(0, t)}{c_{\mathrm{R}}^{*}}\right) \exp \left(-\frac{(1-\alpha) F}{R T} \eta\right)\right]
\end{aligned}
$$

where $\eta$ is the overpotential, defined as the difference between the electrode potential under current flow and the rest (zero current) potential

$\eta=\Phi_{k}-\Phi_{p}-E_{\mathrm{eq}}$

where $\Phi_{k}$ is the potential in phase $k$, and $E_{\text {eq }}$ is the Nernst potential, which is related to the concentrations of the oxidized $\left(c_{\mathrm{O}}^{*}\right)$ and reduced $\left(c_{\mathrm{R}}^{*}\right)$ species by 
$E_{\text {eq }}=E^{0}+\frac{R T}{F} \ln \left(\frac{c_{\mathrm{O}}^{*}}{c_{\mathrm{R}}^{*}}\right)$

where $i_{0}$ is the exchange current density, $\alpha$ is the transfer coefficient (or the symmetry factor in transition state theory), and $R, T$ and $F$ have their usual meaning. This form of the Butler-Volmer equation is important for both fundamental (experimental) kinetic studies and for modeling practical devices, since in both cases one needs to consider the contribution of mass transport of the ions from the bulk solution to the electrode surface.

The essential kinetic parameters determined experimentally are the exchange current density and the transfer coefficient. The exchange current is the magnitude of the partial anodic and cathodic currents which are equal at equilibrium, and are in turn related to the bulk concentrations by the standard rate constant, $k^{0}$,

$i_{0}=F k^{0} c_{\mathrm{O}}^{*(1-\alpha)} c_{\mathrm{R}}^{* \alpha}$

Since the exchange current density varies with the concentration of the redox species, the more fundamental measure of kinetics for redox reactions is $k^{0}$. The grouped kinetic parameter $i_{0}$ is an important quantity to confirm experimentally. The transfer coefficient is usually measured from the slope of $\log i$ vs. $\eta$ in the so-called Tafel region, where the back-reaction is negligible and the relationship between overpotential and current density reduces to

$i=i_{0}\left(\frac{c_{\mathrm{R}}(0, t)}{c_{\mathrm{R}}^{*}}\right) \exp \left(\frac{(1-\alpha) F}{R T} \eta\right)$

and the experimental current is either obtained under conditions where $c_{\mathrm{R}}(0, t)=c_{\mathrm{R}}^{*}$ or accurate mathematical correction can be made to the experimental value, for example, the solution of the convective-diffusion equation for the rotating-disk electrode [85]. Likewise, the value of $i_{0}$ can be obtained by extrapolation of the Tafel plot to $\eta=0$. However, for fast kinetics, or where a second electrochemical reaction (e.g. hydrogen or oxygen evolution), occurs near the equilibrium potential, a linear Tafel plot may not be obtained and neither $i_{0}$ nor $\alpha$ may be obtained by this method. There are a number of other methods that may be used to obtain $i_{0}$ directly. In those cases, the concentration dependence of the exchange current density may be used to obtain $\alpha$.

Following the pioneering theoretical framework introduced by Gerischer [86], modern quantum chemical theory of redox kinetics at electrode surfaces has focused on the distance of the redox ion from the electrode surface [87]. Modern theory typically distinguishes redox reactions as either "inner-sphere" or "outer-sphere", the latter referring to reactions where the redox ion is "inside" the plane of the inner Helmholtz ionic layer and the former "outside" [88].
Practically, this distinction is important in that inner-sphere reactions typically have a very large dependence of the reaction kinetics on the electrode material, in many cases by orders of magnitude; the hydrogen electrode is perhaps the most dramatic in this respect. For outer-sphere reactions, the kinetic effect of different electrode materials is much less, but not insignificant. However, this distinction in electrode-material dependence is not essential, and there are examples where inner-sphere reactions have a relatively small dependence on the electrode material, e.g. the $\mathrm{Br}_{2} / \mathrm{Br}^{-}$reaction. The detailed discussion of the effect of electrode materials on the kinetics is beyond the scope of this review.

One can estimate the rough order of magnitude that the kinetic rate must be for a practical RFB. For example, using some of the metrics in Table 1 (i.e., a RFB must have high electrical efficiency, e.g. at least $80 \%$ round-trip, or $90 \%$ in each direction) and assuming a typical cell voltage of $1.5 \mathrm{~V}$, then the kinetic overpotential must be less than $150 \mathrm{mV}$ throughout the charge/discharge cycle. Assuming a minimum practical current density of at least $50 \mathrm{~mA} / \mathrm{cm}^{2}$, a roughness factor of 10 , i.e. $10 \mathrm{~cm}^{2}$ surface per unit electrode geometric area, and a transfer coefficient of 0.5 , the exchange current density must be greater than $0.3 \mathrm{~mA} /$ $\mathrm{cm}^{2}$ (real) throughout the charge/discharge cycle. Assuming $1 \mathrm{M}$ solutions at $50 \%$ state of charge, and assuming $90 \%$ utilization of the redox ions in the cycle, the minimum value of the standard rate constant $k^{0}$ is ca. $10^{-5} \mathrm{~cm} / \mathrm{s}$. If the rate constant is significantly less than this value, some compromises must be made to achieve a practical device which may increase cost and/or utility. For example, higher surface area/porosity electrodes will compromise a simple flow-by/through design. Reduced current density will reduce power density and result in larger electrodes and more material per unit volume in the RFB. The estimated value above can be compared to those in literature as shown in Table 2.

The results in Table 2 show that of all the redox couples recently or currently in use in practical RFBs, only the $\mathrm{VO}^{2+} / \mathrm{VO}_{2}{ }^{+}$couple has a clear kinetic limitation and, in fact, is clearly problematic. This is not surprising since this redox is not a simple one-electron transfer reaction, but is in modern terminology an oxygen transfer reaction as shown in Eq. 8. As discussed in detail recently by Gattrell et al. [91], this reaction is a multi-step reaction in which oxygen transfer (a chemical step) may precede or follow an electron-transfer step, denoted in modern terminology as a $\mathrm{CE}$ or EC mechanism. Such reactions usually have currentpotential relations which differ significantly from the ideal Butler-Volmer form, and that is the case here. The kinetic data by Gattrell et al. were obtained using a graphite RDE, which should be directly applicable to practical cells which use carbon-felt electrodes. Although the quantitative data 
Table 2 Kinetic parameters for redox reactions used in flow batteries

Supporting electrolyte in most cases is $1 \mathrm{M} \mathrm{H}_{2} \mathrm{SO}_{4}$ or $\mathrm{HClO}_{4}$; concentration of redox species is $10^{-3}$ to $10^{-2} \mathrm{M}$

\begin{tabular}{lccll}
\hline Redox couple & $\alpha$ & \multicolumn{1}{c}{$k_{0}(\mathrm{~cm} / \mathrm{s})$} & Electrode & Reference \\
\hline $\mathrm{Fe}^{3+} / \mathrm{Fe}^{2+}$ & 0.59 & $2.2 \times 10^{-5}$ & $\mathrm{Au}($ poly $)$ & {$[89]$} \\
& 0.55 & $1.2 \times 10^{-5}$ & $\mathrm{Au}(111)$ & {$[62]$} \\
$\mathrm{Cr}^{3+} / \mathrm{Cr}^{2+}$ & $\sim 0.5$ & $2 \times 10^{-4}$ & $\mathrm{Hg}$ & {$[90]$} \\
$\mathrm{VO}_{2}{ }^{+} / \mathrm{VO}^{2+}$ & 0.42 & $3.0 \times 10^{-7}$ & Graphite & {$[91]$} \\
& 0.3 & $1-3 \times 10^{-6}$ & Carbon & {$[92]$} \\
$\mathrm{V}^{3+} / \mathrm{V}^{2+}$ & 0.5 & $4 \times 10^{-3}$ & $\mathrm{Hg}$ & {$[90]$} \\
$\mathrm{Ce}^{4+} / \mathrm{Ce}^{3+}$ & $\sim 0.5$ & $1.6 \times 10^{-3}$ & $\mathrm{Pt}$ & {$[84]$} \\
$\mathrm{Br}_{2} / \mathrm{Br}^{-}$ & 0.35 & $1.7 \times 10^{-2}$ & $\mathrm{Pt}($ poly $)$ & {$[93]$} \\
& 0.46 & $5.8 \times 10^{-4}$ & Vitreous carbon & {$[94]$} \\
\hline
\end{tabular}

in Table 2 was obtained using a $\mathrm{Hg}$ electrode, the polarization curves shown for the $\mathrm{V}^{2+} / \mathrm{V}^{3+}$ electrode with a graphite $\mathrm{RDE}$ in Gattrell et al. indicate a rate constant $\gg 10^{-5} \mathrm{~cm} / \mathrm{s}$.

The dependence of the $\mathrm{VO}^{2+} / \mathrm{VO}_{2}{ }^{+}$couple on electrode material has not been very well-studied. Skyllas-Kazacos and co-workers [92] reported somewhat larger exchangecurrent densities for less well-characterized "carbon" electrodes than Gattrell et al. and suggested it is possible to enhance kinetics by surface treatment of carbon-based electrodes. Zhong et al. fabricated conducting polyethylene (PE) composite electrodes with low resistivities by mixing PE with conducting fillers (carbon black, graphite power and fiber) [92]. The chemical treatment of graphite fiberbased composite polymer electrodes with chromate-sulphuric acid was shown to enhance the surface and improve reactivity for the electrode reactions. Carbon-polypropylene (PP) composite electrodes modified with rubber show better mechanical properties, better impermeability and better overall conductivity compared to the PE composite electrodes [95]. A voltage efficiency as high as $91 \%$ was obtained for the VRB with the carbon-PP composite electrodes. Graphene oxide nanoplatelets (GONPs) demonstrated a more favorable electrocatalytic activity for $\mathrm{V}(\mathrm{V})$ / $\mathrm{V}(\mathrm{IV})$ and $\mathrm{V}$ (III)/V(II) redox couples than pristine graphite for the VRBs. It is found that the V(III)/V(II) redox reaction strongly depends on the formation of surface active functional groups of $\mathrm{C}-\mathrm{OH}$ and $\mathrm{COOH}$ [96]. However, it is not clear that using an electrode material other than graphite/carbon would be cost effective.

In contemporary studies of heterogeneous electron transfer reactions, the $\mathrm{Fe}^{3+} / \mathrm{Fe}^{2+}$ reaction is still considered to be the prototypical outer-sphere reaction amenable to quantitative quantum chemical treatment using modern $\mathrm{ab}$ initio methods. The data shown in Table 2 are relatively recent measurements using sulfuric-acid solutions rigorously purified specifically of chloride ion (to ppb levels). Following the pioneering work by Nagy et al. [97], it is now widely recognized that with $\mathrm{Pt}$ and $\mathrm{Au}$ electrodes, the presence of even trace amounts of chloride ion enhances the experimental rate of electron transfer by at least twoorders of magnitude, probably by a mediated or bridging transfer of the electron via adsorbed chloride anions. While it has not been proven conclusively that the "chloride effect" is exclusive to $\mathrm{Pt}$ and $\mathrm{Au}$, theoretical considerations are consistent with such an expectation, and qualitative data with carbon-felt electrodes suggest this is the case, and that the kinetic parameters given in Table 2 should be applicable to carbon electrodes in a practical battery.

The $\mathrm{Ce}^{4+} / \mathrm{Ce}^{3+}$ was studied in detail by Vetter [84] including rigorous correction for the partial current from oxygen evolution. The reaction has not been the subject of many studies since then. The corrosion of the electrode material and the parasitic effect of oxygen evolution are serious issues for a practical device. Use of stable electrode materials such as $\mathrm{IrO}_{2}$ evolve significant oxygen, thereby reducing efficiency and requiring active cell rebalancing and maintenance. Carbon electrodes will undergo significant corrosion and not have practical lifetimes at these operating potentials [98]. Practical use of this redox couple in a RFB will require a scientific breakthrough in electrode material.

Like the $\mathrm{VO}^{2+} / \mathrm{VO}_{2}{ }^{+}$couple, the $\mathrm{Br}_{2} / \mathrm{Br}^{-}$is a multi-step reaction with at least one chemical step, that of breaking/ making the $\mathrm{Br}-\mathrm{Br}$ bond, either preceding or following electron transfer. The chemical step is, however, much simpler than the oxygen transfer step in the $\mathrm{VO}^{2+} / \mathrm{VO}_{2}{ }^{+}$ reaction. The kinetics of this reaction are not nearly as dependent on electrode material as, for example, the hydrogen electrode, to which it is mechanistically similar [84]. The data for Pt and vitreous carbon shown in Table 2 illustrate this fact well, with the difference in rate constant being only a factor 30 , whereas for the hydrogen electrode the difference would be several orders of magnitude. The reason for this difference can be explained rather easily qualitatively by considering the bond energies involved in the possible/probable chemical steps, for example, that of dissociating the $\mathrm{Br}_{2}$ molecule to form an adsorbed state 
of $\mathrm{Br}$, analogous to the Tafel step in the hydrogen electrode. The bond energy of $\mathrm{Br}_{2}$ is 192 vs. $457 \mathrm{~kJ} / \mathrm{mol}$ for $\mathrm{H}_{2}$. To be energetically favorable, the adsorption energy of the $\mathrm{Br}$ needs to be greater than 86 vs. $228.5 \mathrm{~kJ} / \mathrm{mol}$ for $\mathrm{H}$. If one-electron transfer precedes dissociation, i.e. the dissociation is of $\mathrm{a} \mathrm{Br}_{2}^{-}$species, then the adsorption energy required is even less. Similar considerations apply in the anodic direction, where the proton is much more strongly solvated than the bromide ion (by about a factor of 3 [99]), meaning much weaker chemical interaction with the electrode is required for forming an adsorbed $\mathrm{Br}$ intermediate than an $\mathrm{H}$ intermediate. The shapes of the polarization curves on both $\mathrm{Pt}$ and vitreous carbon are very similar, differing primarily in the magnitude of the current scale, and on neither electrode material does one observe a classic Butler-Volmer relation. For the purposes of Table 2, only the reduction data was used to extract a rate constant using the Tafel region. The authors of both papers propose the same reaction mechanism for both electrode materials,

$\mathrm{Br}_{2}+e^{-} \leftrightharpoons \mathrm{Br}_{\mathrm{ad}}+\mathrm{Br}^{-}$

and

$\mathrm{Br}_{\mathrm{ad}}+e^{-} \leftrightharpoons \mathrm{Br}^{-}$

The first step above is not an elementary step, and electron transfer must either precede or follow dissociation. From the energetic considerations above, it seems reasonable to suggest that on carbon electrodes the electron transfer precedes dissociation, consistent with relatively weak adsorption of $\mathrm{Br}_{\mathrm{ad}}$ on this surface. In many ways, the $\mathrm{Br}_{2} / \mathrm{Br}^{-}$couple is the ideal redox electrode for RFBs. The reaction is relatively facile, and the kinetics are not strongly dependent on electrode material, such that carbon/ graphite electrodes provide reasonable performance, as demonstrated in zinc/bromine RFBs [60]. This material flexibility is a significant advantage in practical electrode design.

Before examining surface-area effects, a mention should be made about typical RFB electrode materials. As noted above, graphitic or vitreous carbon materials are widely used in RFBs [27, 28, 30, 100], such as graphite, carbon felt, carbon fiber, thermal and acid treated graphite, carbonpolymer composite materials, carbon nanotubes, Ir-modified carbon felt and graphene-oxide nanoplatelets. In general, RFB couples are chosen for the facile kinetics so highly active catalytic materials are not necessary. Nonetheless, it has been found that various surface treatments can lead to improved reaction kinetics on carbon electrodes. Chemical etching [101], thermal treatment [102], chemical doping [11], carbon nanotube addition [103], and addition of metallic catalyst sites to the carbon fibers [104] have all been attempted. Aside from catalytic activity, the main criteria for electrode materials are electrical conductivity, chemical stability and durability in the reaction environment. Carbon and graphite materials meet both these requirements, though metal foams and meshes are also candidates $[105,106]$. The search for improved electroactive materials for RFBs will no doubt continue to be actively pursued.

\subsection{Active surface area}

The above kinetic constants and equations (e.g., Eq. 18) are for rates per unit catalyst area. As mentioned, one way to compensate for a slower reaction is to increase the roughness factor or catalyst surface area per unit geometric area. For example, ignoring double-layer charging and assuming electroneutrality, one can write a current balance between ionic and electronic current,

$\nabla \cdot \mathbf{i}_{2}=-\nabla \cdot \mathbf{i}_{1}=a_{1,2} i_{h, 1-2}$

where it is evident that the current generation source term is directly proportional to the specific interfacial area, $a_{1,2}$, which can be related to the roughness factor discussed above Table 2 by accounting for the thickness of the electrode. In the above equation, $-\nabla \cdot \mathbf{i}_{1}$ represents the total anodic rate of electrochemical reactions per unit volume of electrode and $i_{h, 1-2}$ is the transfer current for reaction $h$ between the ionic and electronic materials; for RFBs, the electronic current (1) is the electrons and the ionic current (2) are the reactive ion species. Thus, the surface area in the porous electrode is critical to RFB performance.

An optimum surface area in a porous medium is directly linked to the physical and transport properties of the medium, namely, porosity and permeability, respectively. From an electrochemical standpoint it is desirable to have the highest possible surface area, but this tends to conflict with the need to minimize pressure drop and pumping costs, which favor high permeability. A brief analysis of the interplay between these two key parameters follows. Typical RFB carbon-fiber-paper or carbon-felt electrode materials have a porosity around 0.8 , a fiber diameter of approximately $10 \mu \mathrm{m}$ and a permeability of $20 \times 10^{-8} \mathrm{~cm}^{2}$. A qualitative estimate of the surface area variation with fiber diameter can be obtained using a filament analogue model which simply involves finding the number of cylinders $N$ of a given diameter $d_{\mathrm{f}}$ that give a specified porosity $\varepsilon\left(\mathrm{cm}^{3} / \mathrm{cm}^{3}\right)$, then determining the specific surface area $a_{1,2}\left(\mathrm{~cm}^{2} / \mathrm{cm}^{3}\right)$ of $N$ cylinders. A simple formula for this relationship is given by Carta et al. [107]

$a_{1,2}=\frac{4(1-\varepsilon)}{d_{\mathrm{f}}}$

Figure 7 shows the variation of total surface area as a function of fiber diameter for an $80 \%$ porous material. 


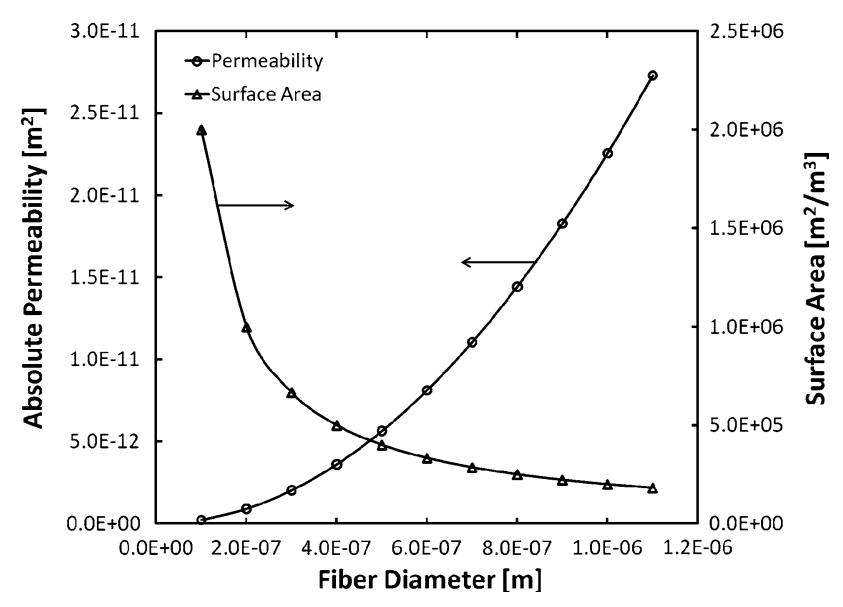

Fig. 7 Permeability and surface area of a fibrous material with a porosity of 0.8 as a function of fiber diameter. Permeability was calculated using the Carman-Kozeny model and surface area was estimated using the filament analogue model

The actual surface area in a real fiber bed may be less than this value since fibers contact and overlap each other, or more if the fibers are not truly cylindrical but rough or ridged. In terms of a roughness factor, using a typical felt properties and a thickness of a few millimeters, a value of around 50 is obtained. Also shown in Fig. 7 is the absolutepermeability change expected as calculated from the Carman-Kozeny equation [108], which has been shown to adequately describe the variation of permeability with porosity due to compression in fibrous materials [109] and is assumed to apply here.

Clearly, the fiber diameter dramatically impacts both aspects and unfortunately in opposing directions. Increasing the fiber diameter from 10 to $100 \mu \mathrm{m}$ improves the permeability by a factor of 100 , but reduces the surface area by a factor of 10 . The same general trend would be true for other random electrodes such as particulate beds. Efforts to increase active surface area in a flowing electrolyte by using particles with microporosity have been reported [18], but, not surprisingly, this additional surface area does not contribute significantly to the electrochemically active area since such internal surfaces are highly diffusion limited. Attempts to increase the roughness of the electrode surface could be beneficial, but typically it is more profitable to modify the surface for increased kinetic or catalytic behavior rather than just surface area.

Another aspect of the active solid surface area that must be considered is the intimacy of the solid/electrolyte contact $[18,36]$. Carbon and graphite materials have a neutral wettability to water [110] which prevents the spreading of electrolyte over the electrode surface. The trapped air pockets resulting from incomplete wetting reduce the electroactive surface area owing to the Cassie-Baxter effect. Such incomplete wetting would be exacerbated on roughened surfaces. Sun and Skyllas-Kazacos found that certain electrode pretreatments intended to improve catalytic activity also lead to somewhat improved wettability behavior [36]. Litster et al. [111] report that briefly heating carbon fiber materials at $300{ }^{\circ} \mathrm{C}$ in an air environment rendered them fully hydrophilic, and Yan et al. [112] review various treatment procedures for altering carbon wettability. The presence of a gas phase at the solid/ electrolyte interface could be due to residual air trapped during initial flooding of the electrode, or could appear due to evolution of gases such as the parasitic evolution of hydrogen and/or oxygen [13, 113].

\section{Transport phenomena}

There are various mechanisms of transport that occur within a RFB. Typically, electron flow is not limiting due to the use of conductive additives or just carbon materials. This transport is adequately described by Ohm's law,

$\mathbf{i}_{1}=-\sigma \nabla \Phi_{1}$

where $\sigma$ is the electronic conductivity. The other major transport issue is that of the reactants and products. Typically, this can be separated into two different regions, namely, that of the electrode and that of the membrane or separator. These two regions often have different properties; their transport species and mechanisms are discussed in turn below. For the electrolyte in the electrodes, diffusion is often the most important process while conduction is for the membrane. Table 3 shows a summary of the charge-carrying species across the membrane, open circuit potential, and diffusivities of active ions. While dilutesolution theory does not necessarily strictly apply in the electrolyte systems of interest, diffusivities of the ions give a good indication of the relative motions of the relevant ions. Cation-exchange membranes (mainly $\mathrm{H}^{+}$and $\mathrm{Na}^{+}$) are widely used in the aqueous RFBs due to their high ionic conductivity. Anion exchange membranes are used in many non-aqueous systems to be compatible with the supporting electrolytes used and suppress unwanted crossover. Generally, the open-circuit potential of an aqueous system is constrained to be lower due to the low electrochemical stability window of $\mathrm{H}_{2} \mathrm{O}$ compared to that of non-aqueous RFB's, in which organic solvents (such as acetone) with a higher electrochemical stability voltage window are used. The diffusivities of active species in all systems listed in Table 3 are in the range of 1.6 to $12 \times 10^{-6} \mathrm{~cm}^{2} / \mathrm{s}$ except for V(IV) $\left(1770 \times 10^{-6} \mathrm{~cm}^{2} / \mathrm{s}\right.$ in 6.4 $\mathrm{M} \mathrm{HBr}$ and $2 \mathrm{M} \mathrm{HCl}$ ). Finally, while there are some other, less critical issues such as thermal management and heat transport within the cell, such a discussion is beyond the scope of this review. 
Table 3 Summary of different thermodynamic and transport parameters for various RFBs

\begin{tabular}{|c|c|c|c|c|c|}
\hline RFB & $\begin{array}{l}\text { Membrane } \\
\text { charge carrier }\end{array}$ & $\begin{array}{l}\text { Open-circuit } \\
\text { potential }(\mathrm{V})\end{array}$ & Diffusivity, $D\left(10^{-6} \mathrm{~cm}^{2} / \mathrm{s}\right)$ & & Reference \\
\hline \multirow[t]{2}{*}{ All vanadium } & \multirow[t]{2}{*}{$\mathrm{H}^{+}$} & \multirow[t]{2}{*}{1.26} & $\begin{array}{l}\mathrm{VCl}_{3}+\mathrm{H}_{2} \mathrm{SO}_{4} / \mathrm{Na}_{2} \mathrm{SO}_{4} \text {, glassy } \\
\text { carbon electrode }\end{array}$ & $\begin{array}{l}1.50(\mathrm{pH}=4.0) \\
1.34(\mathrm{pH}=2.0) \\
1.16(\mathrm{pH}=1.0) \\
1.41(\mathrm{pH}=0.0)\end{array}$ & [29] \\
\hline & & & $\begin{array}{l}\mathrm{V}_{2} \mathrm{O}_{5}+1.8 \mathrm{M} \mathrm{H}_{2} \mathrm{SO}_{4} / \mathrm{Na}_{2} \mathrm{SO}_{4} \\
\text { glassy carbon electrode }\end{array}$ & 5.7 & [29] \\
\hline Vanadium/bromine & $\mathrm{H}^{+}$ & 1.1 & $\mathrm{~V}(\mathrm{IV})+6.4 \mathrm{M} \mathrm{HBr}, 2 \mathrm{M} \mathrm{HCl}$ solution & 1770 & {$[50]$} \\
\hline Iron/chromium & $\mathrm{Cl}^{-} / \mathrm{H}^{+}$ & $0.77-1.03$ & $\begin{array}{l}\mathrm{Fe}(\mathrm{III}) \\
\mathrm{Cr}(\mathrm{III})\end{array}$ & $\begin{array}{l}6 \\
6\end{array}$ & [19] \\
\hline Zinc/bromine & $\mathrm{H}^{+}$ & 1.85 & $\mathrm{Zn}^{2+}$ & 7.54 & {$[58]$} \\
\hline Zinc/cerium & $\mathrm{H}^{+}$ & 2.2 & $\mathrm{Ce}(\mathrm{III})$ ion in methanesulfonic acid & $0.27-0.72$ & [117] \\
\hline Bromine/polysulphide & $\mathrm{Na}^{+}$ & 1.54 & $\begin{array}{l}\mathrm{Br}^{-} \\
\mathrm{Br}_{3}^{-} \\
\mathrm{S}_{2}^{2-} \\
\mathrm{S}_{4}^{2-}\end{array}$ & $\begin{array}{l}12 \\
5 \\
6 \\
5\end{array}$ & {$[22]$} \\
\hline $\begin{array}{l}\mathrm{Fe}(\mathrm{III}) / \mathrm{Fe}(\mathrm{II}) \\
\quad \text { triethanolamine/bromine }\end{array}$ & $\mathrm{Na}^{+}$ & 1.0 & N/A & 1.63 & {$[64]$} \\
\hline $\begin{array}{l}\text { Non-aqueous vanadium } \\
\text { acetylacetonate }\end{array}$ & $\mathrm{BF}_{4}^{-}$ & 2.2 & $\mathrm{~V}(\mathrm{acac})_{3}$ & $1.8-2.9$ & {$[66]$} \\
\hline
\end{tabular}

\subsection{Electrolyte flow}

Within the electrode, the flux of the various species can be described using the Nernst-Planck equation assuming that dilute-solution theory holds [114]

$\mathbf{N}_{i}=-z_{i} u_{i} F c_{i} \nabla \Phi_{2}-D_{i} \nabla c_{i}+c_{i} \mathbf{v}$

The first term in the expression is a migration term, representing the motion of charged species that results from a potential gradient. The migration flux is related to the potential gradient $\left(-\nabla \Phi_{2}\right)$ by a charge number, $z_{i}$, concentration, $c_{i}$, and mobility, $u_{i}$. The second term relates the diffusive flux to the concentration gradient. The final term is a convective term and represents the motion of the species as the bulk motion of the solvent carries it along. For noncharged reactants and products (e.g., $\mathrm{Br}_{2}$ ), the same equation can be used with the migration term set to zero, resulting in the equation of convective diffusion [115]. Dilute-solution theory considers only the interactions between each dissolved species and the solvent, and thus one can consider the conductivity of the solution to be given by

$\kappa=F^{2} \sum_{i} z_{i}^{2} c_{i} u_{i}$

The motion of each charged species is described by its transport properties, namely, the mobility and the diffusion coefficient. These transport properties can be related to one another at infinite dilution via the Nernst-Einstein equation $[114,116,117]$
$D_{i}=R T u_{i}$

For more complicated systems than binary electrolytes or where the interactions between species are important and/ or non-ideal, concentrated-solution theory can be used as discussed by Newman and Thomas-Alyea [114]. In this approach, the transport coefficients of merit include the conductivity of the solution, and the transference numbers and diffusivities of the ions. It should be noted that many RFBs operate at higher concentrations such that concentrated-solution theory may be required; however, the use of supporting electrolytes does mitigate this to a certain extent in that detailed speciation is not required to predict cell performance fairly well.

The total current in the electrolyte can be expressed as

$\mathbf{i}_{2}=F \sum_{i} z_{i} \mathbf{N}_{i}$

and the ionic conductivity of the electrolyte can be related to the above transport properties [114].

For most RFB applications, the system is one phase (liquid) and so complicated expressions for multiphase flow are unnecessary, in stark contrast to low-temperature fuel cells [118]. Thus, for the convective flow one can use the Navier-Stokes equations [115]

$\mathbf{v} \cdot \nabla(\rho \mathbf{v})=-\nabla p+\mu \nabla^{2} \mathbf{v}$

where $p$ is the pressure, and $\mu$ and $\rho$ are the viscosity and density of the liquid, respectively. Since most RFB 
electrodes are porous, the above equation can be extended using various methodologies such as Brinkman [108, 115, 119], or even replaced by Darcy's law [108]

$\mathbf{v}=-\frac{k}{\mu} \nabla p$

Flowing electrolyte through porous electrodes presents a number of challenges, both at the single-cell and full-stack level. At the pore scale within each electrode there will be significant differences in the interstitial flowrate in each pore owing to size differences, with flow largely confined to the largest pores in the medium. Such pore-scale-channeling behavior provides convective mass transport at a limited number of surfaces, while dead zones of relatively stagnant flow and localized limiting currents would exist elsewhere throughout the electrode. Fibrous materials are the favored porous-electrode substrate for several reasons because high porosity can be achieved while still maintaining electrical conductivity and percolation in the solid phase due the bridging between long fibers. As discussed above, high porosity is advantageous since (a) there is a strong positive correlation between porosity and permeability [113], thereby resulting in reduced pressure drop and associated pumping costs; and (b) the effective ionic conductivity of the electrolyte is directly proportional to porosity [120] and inversely proportional to tortuosity which tends to increase with decreasing porosity [113].

Due to the wide spread use of fibrous electrodes for various applications, a number of studies have looked at mass transfer in carbon-fiber electrodes [66, 121-124]. Schmal et al. [66] compared mass transfer at single fibers to fiber assemblies (bundles and felts) and found that per unit length of fiber the mass transfer to a single fiber was significantly higher. This was attributed to channeling within the fiber assemblies causing dead-zones or stagnant regions, effectively reducing the active area for reaction. A porous material with very uniform pore-size distribution would help alleviate this problem, but such materials may be impractical. Saleh [125] studied the effectiveness factor in packed bed electrodes and found that ohmic resistance, which is a combination of fluid properties and bed geometry, also played a key role in determining the extent to which the porous electrode was utilized.

Another cell-scale issue arising from the convective flow in porous electrodes is large scale heterogeneities due to assembly tolerances or uneven thermal expansion, which could lead to bypassing of large sections of a cell. Moreover, flow through porous electrodes presents major manifolding issues at the stack-scale since each cell must have nearly identical permeability. This would be difficult to achieve since stacks may be compressed significantly when assembled. This situation is analogous to interdigitated flow fields proposed for low-temperature fuel cells, which showed very promising performance results in single-cell tests, but the inevitable differences in permeability from cell to cell in a stack created uneven flow distribution among cells [126].

To enhance flow and electrolyte utilization during deep discharge where high flow rates are required, physical barriers or roughened electrode materials can be used inside the cell to promote turbulence and mass transport. Lessner et al. designed a flow-through porous electrode for bromine/polysulphide RFBs [24]. To ensure uniform flow distribution and prevent channeling, quartz particles (with diameter of 0.5 to $1.0 \mathrm{~mm}$ ) were placed $0.5 \mathrm{~cm}$ above the inlet. Based on the results, the relationship between dimensionless mass transfer rate (Sherwood number, Sh) and Reynolds number $R e$ for their geometry was obtained $S h=14.29 R e^{0.348}$

This functional dependence on $R e$ is in excellent agreement with Sioda's [127] and Cano and Bohm's [128] findings.

Leung et al. also investigated the effect of the mean linear flow velocity of the electrolyte on the cell performance both under constant current charge and discharge [70]. Figure 8 presents the effect of the mean linear flow velocity on the discharge voltage with different constant discharge current densities. It is shown that there is a maximum cell voltage at the mean linear flow velocity of $3.9 \mathrm{~cm} / \mathrm{s}$.

\subsubsection{Reactant concentration effects}

The issue of reactant solubility in the flowing electrolyte solution can be important. The energy density of a RFB system is set by the concentration of dissolved species, but the maximum concentration in any stream is limited by the

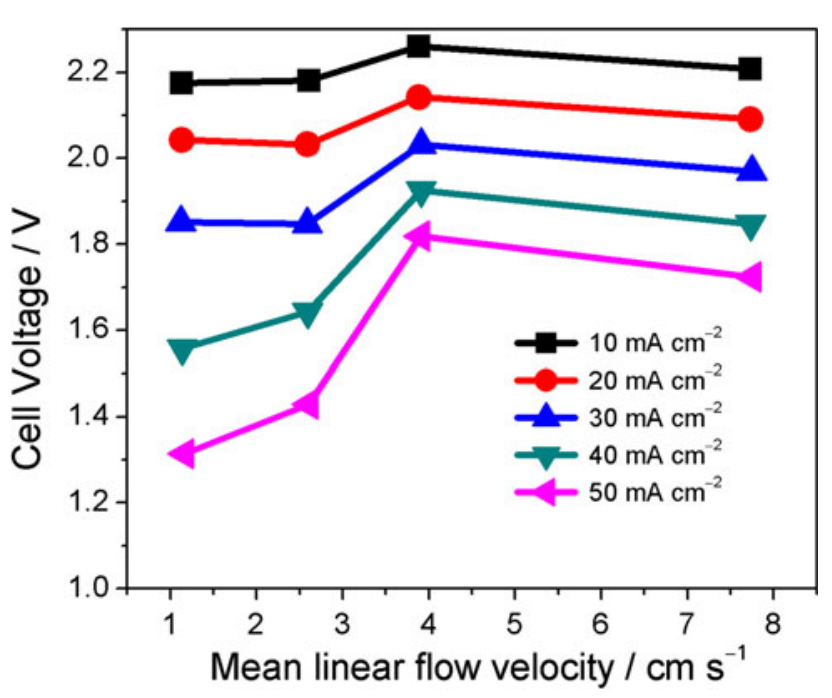

Fig. 8 Effect of the mean linear flow velocity of the electrolyte on the cell voltage of the $\mathrm{Zn} / \mathrm{Ce}$ RFB. Adapted from Ref. [70] with permission 
solubility of the least soluble species. Precipitation of reactants or products in the porous electrode is calamitous. Concentration limits on the electroactive species not only reduces the energy density of a system, but also negatively impacts the power density and cell efficiency as well. Lower concentrations mean reduced mass-transfer rates and current density, thus increasing concentration polarization and/or pumping power. Solubility is a function of temperature as well, which must be factored into cell design. For instance, it is observed that $\mathrm{V}_{2} \mathrm{O}_{5}$ precipitation occurs at elevated temperature, limiting the operating temperature to the range of 10 to $40{ }^{\circ} \mathrm{C}$ [37, 129]. Li et al. improved this situation with the development of a vanadium sulfate and chloride mixed electrolyte, enabling a vanadium concentration up to $2.5 \mathrm{M}$ over a temperature range of -5 to $50{ }^{\circ} \mathrm{C}$ [46]. However, temperature excursions in an operating cell could cause a precipitation event and lead to cell failure [18].

Other issues regarding concentrations include the fact that for many systems increasing the concentration of the reactants can lead to more complexing and lower diffusivities and perhaps even more viscous solutions. For example, recent data measured at LBNL show that $\mathrm{Br}_{2}$ diffusivity decreases by a factor of two as the concentration of $\mathrm{HBr}$ is increased from 1 to $7 \mathrm{M}$ [130]. Such tradeoffs require optimization for the specific system. Another ubiquitous issue present in flowing reactors of all types concerns the extent of reactant conversion, sometimes referred to as utilization or stoichiometry. The difficulty is determining the optimum reactant concentration at the outlet of the electrode. It is desirable or necessary that the electrode near the outlet is not starved of reactant to prevent parasitic reactions such as gas evolution or electrode corrosion. On the other hand, fully consuming or utilizing the reactants means recovery of the maximum amount of energy stored in the solution. For many systems, the stoichiometry is high for single-cell studies (typically over 10) [59], and it is not clear as to how this can be translated into actual systems where such performance would necessitate multiple passes through the electrodes. One such approach would be to have a cascade of reactors that are tailored to specific operating points and concentrations [131].

\subsubsection{Shunt currents}

One of the challenges of stack design that must be given particular attention in RFB configurations is protection against shunt currents. Generally speaking, a shunt current refers to a condition in which current deviates from the intended path, via a parallel path with a sufficiently low resistance to divert a portion of the current. In general, the path of least resistance in a cell or stack is designed to follow the direction of intended current flow. In a flow battery configuration in which cells are configured in series, it is intended for all of the current to flow in the electrolytic phase via ionic conduction from one negative electrode to the adjacent positive electrode, and in the current collector from one adjacent bipolar plate to another. In a well-designed stack, there should be no current flow except directly from one cell to another in the preferred series configuration.

In practice, however, there is no perfectly insulator, and current can flow from one cell to another in such a way that significant power is lost and stack output voltage is lowered. It is possible for stray electronic paths to allow redistribution of current from one cell of a multicell stack to another, and strict requirements on the resistance of stack externals such as manifolds and packaging help to minimize shunt currents via electrical conduction [132]. The same general rules and restrictions that guide conventional battery and stack design and isolation can prevent shunt currents via electrically conducting pathways.

Of particular concern in flow batteries is the development of shunt currents via the liquid electrolyte. While shunt currents can develop in the liquid phase in conventional fuel-cell and battery designs [133, 134], the restriction of the primary electrolyte to the region between each pair of current collectors minimizes most obvious paths for current flow, at least in the electrolytic phase. While fuel cells do distribute fluids from one cell to another via the fuel manifolds, the effective conductivities of liquid-feed fuels and of most coolants are much lower than the conductivities of RFB electrolytes [18].

Because RFBs involve the circulation of electrolyte to each of the individual cells, there is an obvious ionic current path from one cell to another. The currents that flow in the circulating electrolyte from one cell to another via the electrolyte flow manifolds are best managed by increasing the effective resistance of the flow path, either by increasing the effective path length between cell flow inputs and outputs in the manifold, or by reducing the cross-sectional area of the ports. Unfortunately, increasing the resistance in such a way to minimize shunt currents also works to increase the resistance to flow. This has the result of increasing the requirements for parasitic power to circulate the electrolyte through the system; this complicates system design and increases both capital and operating costs. Several researchers have investigated the design implications for flow batteries for particular systems, though optimization will be required for specific electrolyte and cell configurations [135-137].

\subsection{Separators}

There are two main types of RFB separators. The first is a microporous separator that can allow for exchange of 
liquids between the anolyte and catholyte compartments. Such an approach is akin to the discussion above concerning a porous region. Because of this ability to mix, microporous separators often lead to higher rates of reactant and product crossover, and thus lower coulombic efficiencies. For this and other reasons, most RFBs use an ionically conducting membrane as a separator.

The IEM is one of the most critical components in RFBs. In terms of transport, the dual and opposing needs to enhance the desired charge transport while limiting undesired crossover of reactant, product, and other species is an unresolved engineering issue. There are a number of IEMs which have been used in RFBs, with the most common one being Nafion ${ }^{\circledR}$, a perfluorosulfonic acid membrane that binds cations to its sulfonic acid sites [138]. Nafion ${ }^{\circledR}$ is the membrane of choice in many RFBs due to its high proton and sodium conductivities and its proven stability in the chlor-alkali industry. It has a conduction mechanism that includes both hopping and vehicular modalities.

Since most IEMs are single ion conductors (see Table 3), transport within them can often be described using Ohm's law (Eq. 27). If there are other interactions such as electroosmotic flow, this description can be modified; for example, for proton conduction in $\mathrm{Nafion}^{\circledR}$ the following expression can be used [139, 140]

$\mathbf{i}_{2}=-\kappa \nabla \Phi_{2}-\frac{\kappa \xi}{F} \nabla \mu_{0}$

$\mathbf{N}_{0}=-\frac{\kappa \xi}{F} \nabla \Phi_{2}-\left(\alpha+\frac{\kappa \xi^{2}}{F^{2}}\right) \nabla \mu_{0}$

where $\xi$ is the electroosmotic coefficient, $\kappa$ is the ionic conductivity, $\mu_{0}$ is the chemical potential of the solvent, and $\alpha$ is the transport coefficient of the solvent through the membrane. If there are other ions in the solution that penetrate the membrane, it is easiest to describe this motion using a Poisson-Nernst-Planck (PNP) framework where the Nernst-Planck equations are used (Eq. 28) along with Poisson's equation,

$\nabla^{2} \Phi_{2}=-\frac{\rho}{\varepsilon_{0}}$

where $\varepsilon_{0}$ is the permittivity and $\rho$ is the charge density. This methodology accounts for non electroneutrality conditions that exist due to the small charged pathways inside the membrane for conduction. In the above PNP treatment, dilute-solution theory is used and if interactions between species and non-dilute behavior is expected, one can use concentrated-solution theory, which complicates the expressions, requires more knowledge of the transport properties, and is beyond the scope of this paper (for an example, see Delacourt and coworkers [141, 142]). In terms of reactant and product crossover, the easiest way is to use a permeation coefficient, $\psi$, which is a combination of Henry's law and a transport coefficient such as a permeability,

$\mathbf{N}_{i}=\psi_{i} \nabla c_{i}$

Membrane design should consider the following properties: ion conductivity, ion selectivity, permeability, chemical stability, and mechanical properties. A detailed summary of the recent progress of IEM for VRBs can be found in the review by Li et al. [6] and we use the VRB as the example for discussing IEMs and transport; Table 4 shows some IEMs used for the VRB example case.

Skyllas-Kazacos et al. used the Amberlite CG 400 composite membrane in the VRBs. The membranes showed a good stability of more than $4000 \mathrm{~h}[43,44]$. Zhang et al. found that the current efficiency of 94 and $91 \%$ are achieved for Nafion ${ }^{\circledR} 115$ and 112 membranes used in VRBs, respectively [5]. However, the Nafion ${ }^{\circledR}$ membranes suffer from heavy active ion crossover and low ion selectivity. By incorporation of inorganic species (such as $\mathrm{SiO}_{2}$, $\mathrm{TiO}_{2}$, and $\mathrm{ZrP}$ ) into Nafion ${ }^{\circledR}$, the crossover of vanadium ions can be effectively reduced [143, 144, 152]. The ion selectivity can be enhanced using the organic/Nafion ${ }^{\circledR}$ hybrid membranes fabricated with interfacial polymerization and directly blending methods. Xi et al. prepared Nafion ${ }^{\circledR} / \mathrm{SiO}_{2}$ hybrid membranes using in situ sol-gel method, and showed that the vanadium crossover was effectively reduced due to the polar clusters of the original Nafion $^{\circledR}$ [144]. The maximum energy efficiency of the VRB using this membrane was nearly $80 \%$ at $20 \mathrm{~mA} / \mathrm{cm}^{2}$. Luo et al. modified Nafion ${ }^{\circledR} 117$ membrane using interfacial polymerization method for VRB application [153]. Sulfonated poly(tetramethydiphenyl ether ether ketone) (SPEEK) membrane showed one order of magnitude of vanadium ion permeability lower than that of Nafion ${ }^{\circledR} 115$ [145]. In the multiple-cycle tests, the SPEEK40 membrane shows high stability and high columbic efficiency above 98\%. Generally, IEMs prepared with interfacial grafting, blend, radiation, non-fluorinated and hybrid membranes show lower ion permeability than that of Nafion ${ }^{\circledR}$ membrane. However, when $\mathrm{V}^{n+}$ crossover is blocked, the protonic conductivity is also decreased which results in relatively low conductivity. So it is still a critical challenge for IEM development that ion selectivity is enhanced with high ionic conductivity. Vafiadis and Skyllas-Kazacos assessed a range of IEMs in vanadium/bromine RFBs considering ion-exchange capacity, conductivity, vanadium ion diffusion, water content, and chemical stability [51].

In addition to ion transfer, electroosmotic flow can cause transfer of water from one half cell to the other one during the charge-discharge cycles. The direction and magnitude of the transport is affected by the membrane used. Mohammadi et al. studied the water transfer behavior of anion- and cation-exchange membranes in the VRB [43]. 
Table 4 Summary and comparison of ion-exchange membranes used in all-vanadium RFB (VRB)

\begin{tabular}{|c|c|c|c|c|c|c|c|c|c|}
\hline \multirow[t]{2}{*}{ Membrane } & \multirow[t]{2}{*}{ Approach } & \multirow{2}{*}{$\begin{array}{l}\text { Thickness } \\
(\mu \mathrm{m})\end{array}$} & \multirow{2}{*}{$\begin{array}{l}\text { IEC } \\
(\mathrm{mmol} / \mathrm{g})\end{array}$} & \multicolumn{3}{|c|}{ Permeability (ppm) } & \multirow{2}{*}{$\begin{array}{l}\text { Ionic } \\
\text { conductivity } \\
(\mathrm{mS} / \mathrm{cm})\end{array}$} & \multirow{2}{*}{$\begin{array}{l}\text { Liquid } \\
\text { uptake } \\
(\mathrm{wt} \%)\end{array}$} & \multirow[t]{2}{*}{ Reference } \\
\hline & & & & $\mathrm{V}^{3+}$ & $\mathrm{VO}^{2+}$ & $\overline{\mathrm{VO}_{2}{ }^{+}}$ & & & \\
\hline Nafion ${ }^{\circledR} / \mathrm{SiO}_{2}$ & Hybrid & 204 & 0.96 & $<134$ & $<82$ & $<17.8$ & 56.2 & 21.5 & [143] \\
\hline Modified Nafion ${ }^{\circledR} 117$ & Interfacial polymerization & 201 & 0.88 & - & 34.6 & - & 15 & - & [144] \\
\hline SPEEK & Blend & 88 & 1.76 & - & 12.4 & - & 7.5 & 28.6 & {$[145]$} \\
\hline $\begin{array}{l}\text { PVDF-g-PSSA- } \\
\text { co-PMAc }\end{array}$ & Radiation grafting & 70 & 1.95 & 11.2 & 0.73 & 1.1 & 100 & 22 & [146] \\
\hline AIEM & $\begin{array}{l}\text { Two-step radiation-induced } \\
\text { grafting }\end{array}$ & 42 & 0.97 & - & 22 & - & 31 & 25.4 & {$[147]$} \\
\hline SPFEK & Non-fluorinated & - & 1.92 & - & $<125$ & - & 34.8 & 20.5 & {$[148]$} \\
\hline SFPEK & Non-fluorinated & 151 & 1.59 & - & 94 & - & 2.2 & 36 & [149] \\
\hline SPTK & Non-fluorinated & - & 1.29 & - & 12 & - & 10.5 & 11.9 & {$[150]$} \\
\hline SPTKK & Non-fluorinated & - & 1.91 & - & 31 & - & 13.6 & 19.3 & [150] \\
\hline Nafion $^{\circledR} 117$ & PFSA & 178 & 0.94 & $<600$ & $<550$ & $<120$ & 58.7 & 26.0 & [151] \\
\hline Nafion $^{\circledR} 115$ & PFSA & 127 & 0.91 & - & 79.5 & - & 13.4 & 26 & [145] \\
\hline
\end{tabular}

IEC ion exchange capacity

Fig. 9 Various fluxes across cation exchange membrane (a) and anion exchange membrane (b) for the vanadium electrolyte solutions [44]
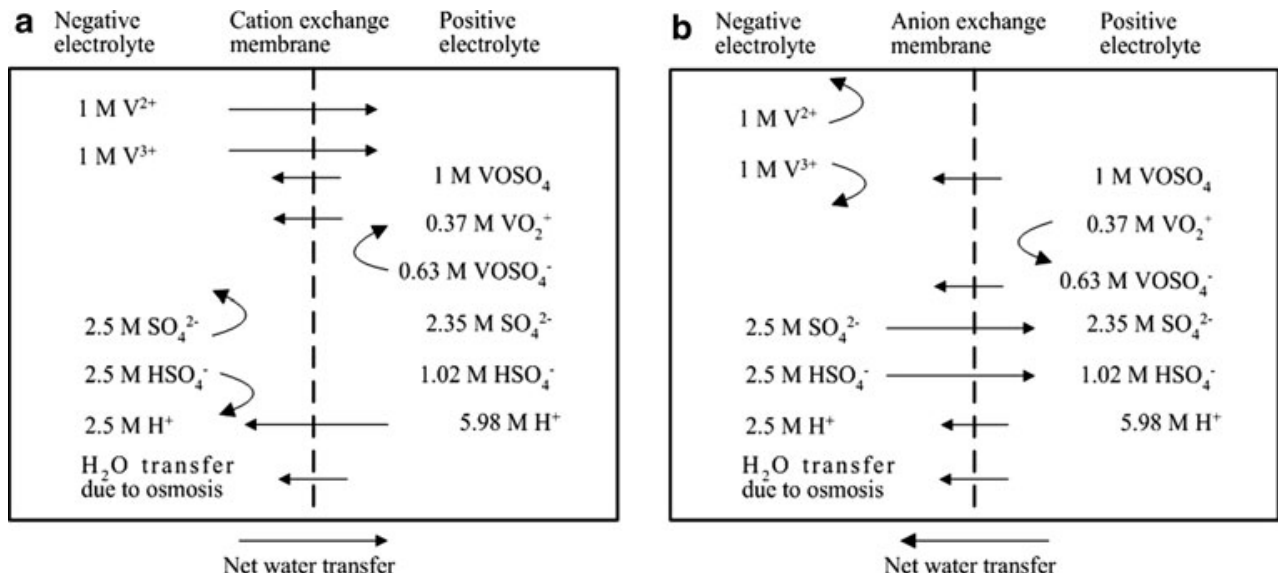

As shown in Fig. 9, a significant amount of water is transferred from the negative-half-cell electrolyte to the positive half cell in a VRB using a cation-exchange membrane such as Nafion ${ }^{\circledR}$. This movement is attributed to the hydration shells of $\mathrm{V}^{2+}$ and $\mathrm{V}^{3+}$ ions which carry a large amount of water and can easily permeate through cation-exchange membranes. For anion-exchange membranes, the permeation of $\mathrm{V}^{2+}$ and $\mathrm{V}^{3+}$ co-ions are restricted. However, there is a net water transfer from the positive half cell to the negative half cell because of the neutral $\mathrm{VOSO}_{4}$ and negative $\mathrm{VO}_{2} \mathrm{SO}_{4}{ }^{-}$in the positive half cell that can readily permeate through the membrane [44].

\section{Cell modeling and design}

The above two section describe transport and kinetics. These descriptions can be combined in overall mass conservation equations of the individual species to track where and how they move through the system [118]

$$
\begin{aligned}
\frac{\partial(1-\varepsilon) c_{i}}{\partial t}= & -\nabla \cdot \mathbf{N}_{i}-\sum_{h} a_{1,2} s_{i, k, h} \frac{i_{h, 1-2}}{n_{h} F} \\
& +\sum_{l} s_{i, 2, l} \sum_{p \neq 1} a_{2, p} r_{l, p}+\sum_{g} s_{i, 2, g}(1-\varepsilon) R_{g}
\end{aligned}
$$

The term on the left side of the equation is the accumulation term, which accounts for the change in the total amount of species $i$ held in phase $k$ within a differential control volume. The first term on the right side of the equation keeps track of the material that enters or leaves the control volume by mass transport. The remaining three terms account for material that is gained or lost due to chemical reactions. The first summation includes all electron-transfer reactions that occur at the interface between phase $k$ and the electronically conducting phase (denoted as 
Fig. 10 Steady-state resistornetwork representation of porous-electrode theory

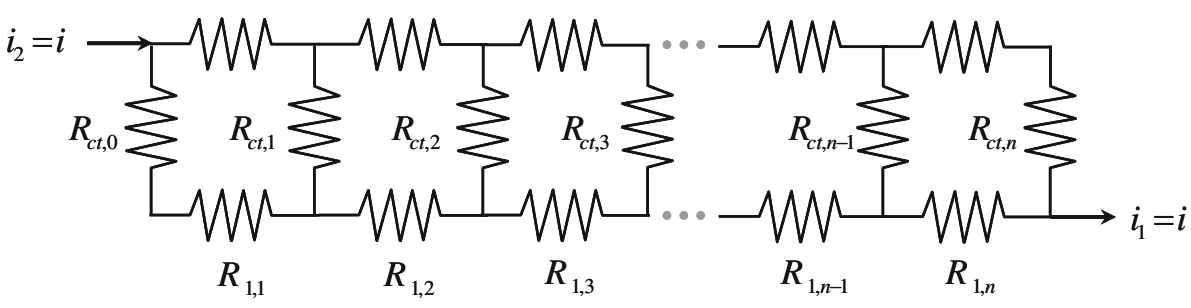

phase 1). The second summation accounts for all other interfacial reactions that do not include electron transfer, and the final term accounts for homogeneous reactions in phase $k$. In the above expression, $\varepsilon$ is the porosity of the domain, $s_{i, k, l}$ is the stoichiometric coefficient of species $i$ in phase $k$ participating in heterogeneous reaction $l, r_{l, p}$ is the rate of the heterogeneous reaction $l$ per unit of interfacial area with phase $p . R_{g}$ is the rate of a strictly homogenous reaction $g$ per unit volume.

The key component in a RFB is the porous electrode where the reactions occur. The fundamentals behind porous electrodes are well established by the work of Newman and coworkers [114, 154]. A porous electrode can be visualized as a resistor network as shown in Fig. 10.

In Fig. 10, the total current density, $i$, flows through the electrolyte phase (2) and the solid phase (1) at each respective end. In between, the current is apportioned based on the resistances in each phase and the chargetransfer resistances. The charge-transfer resistances can be nonlinear because they are based on kinetic expressions. Thus, the reaction will proceed depending on what is limiting. Since kinetics are typically facile in RFB systems, the main issues are reactant and ion movement to and away from the reaction site. For example, if the mass-transfer of a reactant is limiting, then the reaction will proceed near the inlet, whereas if ion conduction is limiting, then it will occur near the separator; a uniform reaction rate is rarely achieved without some kind of mass-transfer control (e.g., a microporous layer limiting flow of a reactant). An interesting issue is that one cannot diagnose what is limiting purely from a polarization curve, since even mass-transfer limitations can appear to be ohmic ones. For example, due to reactant mass-transfer limitations, a reaction may proceed at the electrode surface near the flow inlet yet the performance will look as if it is ohmically limited due to the distance the ions have to travel from the separator to the reaction site. Because of this and other reasons, mathematical modeling is often used to understand the limiting phenomena and processes in a RFB; yet, relative to the experimental and demonstration system development, analytical and computational modeling of RFBs has trailed, which may be due to the era in which they were heavily researched. Advanced modeling is needed to understand fully the various physiochemical phenomena involved to help minimize transport losses and facilitate optimized material design and architectures. The models help lead to optimized porous-electrode structures, which are crucial in increasing RFB performance and hence reducing cost. These issues are explored in more detail in this section.

\subsection{Electrode structure}

RFB can have two basic electrode configurations: flow through a porous $3 \mathrm{D}$ electrode or flow past a planar electrode. These are shown schematically in Fig. 11a, b respectively. Naturally, these two configurations are often referred to as 'flow-through' and 'flow-by' electrodes, but this terminology is somewhat confusing since these two terms are also occasionally used to describe flow parallel and perpendicular to the direction of the current flow [155]. The following discussion will adopt the intuitive use of 'flow-through' a porous electrode and 'flow-by' a planar electrode.

Whether a flow-through or a flow-by electrode can or must be used depends on a number of factors including the physical state of the flowing reactant (i.e. gas or liquid), the electrode reaction occurring (e.g. plating of solid or electron transfer in solution) and the conductivity of the electrolyte phase. For instance, in the prototypical or conventional RFB $[57,58]$ the reactants and products on both the anode and cathode are dissolved ions, and a porous 3D flow-through electrode, as shown in Fig. 11a, is typically used on both sides. In this configuration the liquid electrolyte flows through a porous matrix of electrochemically active solids, usually carbon fibers with appropriate catalytic surface properties. The ions produced by the reaction migrate through the electrolyte phase toward the opposing electrode and the electrons move through the network of carbon fibers to the current collector. The flow-through electrode is well suited to reactions of flowing liquid-phase species for a number of reasons. First, the diffusivity of liquid-phase species is quite low so forced convection through a porous electrode provides enhanced mass-transfer rates. Second, the concentration of reactive ions is generally low due to solubility limits so forced mass transfer helps maintain higher current densities. Finally, the flowing electrolyte will generally have a high ionic conductivity, 
Fig. 11 Schematic diagrams of a flow through electrode, b flow-by electrode with active surface near the current collector (left) and near the membrane separator (right), and c flow-by electrode used in solid-plating cells. Solid arrows indicate convective flow of reactants and dashed arrows represent diffusive paths
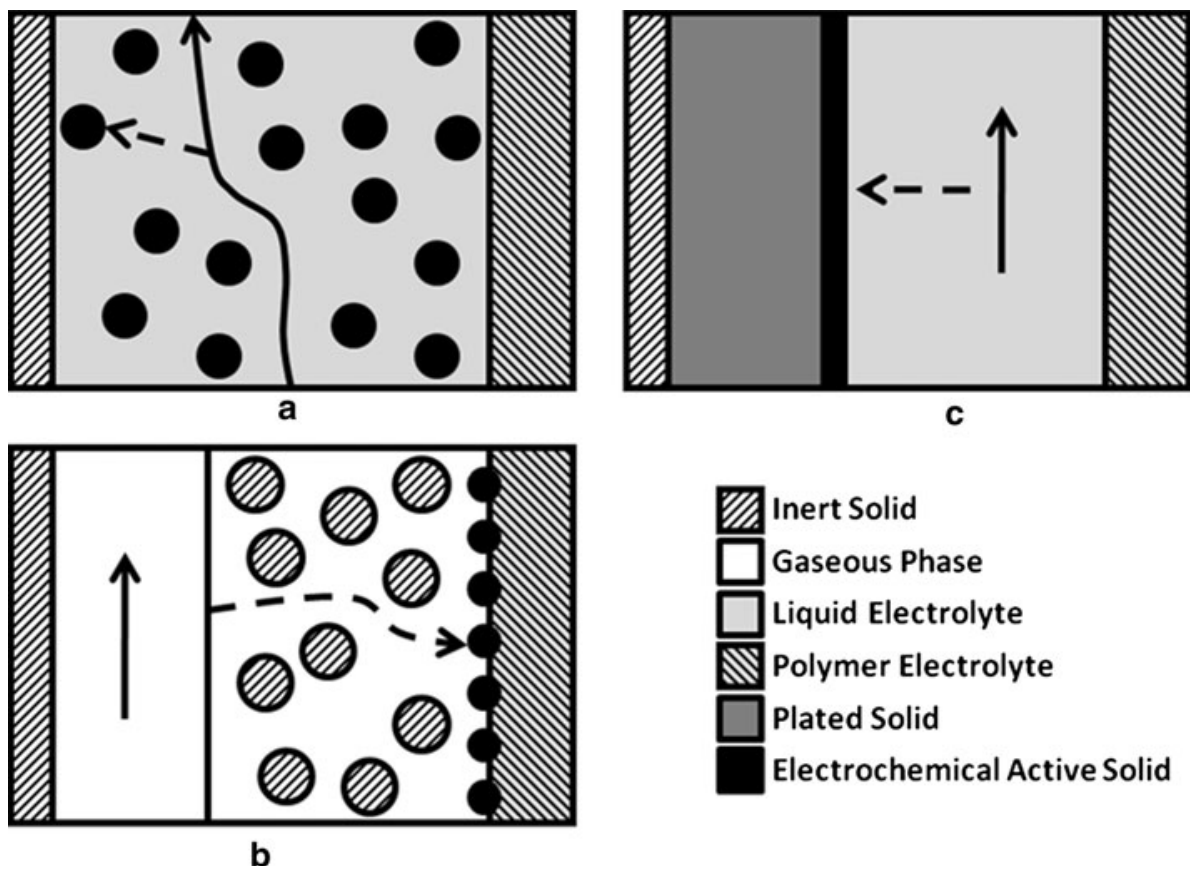

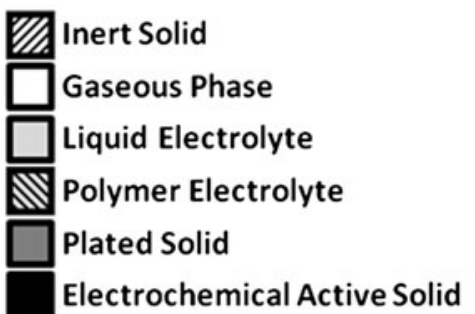

which is necessary to avoid ohmic polarization losses over the long transport lengths created by the 3D configuration.

The planar electrode is most commonly used when a gaseous reactant is involved. A common example is the hydrogen/bromine cell [71] which uses a liquid mixture of bromine and aqueous hydrobromic acid on the cathode with a flow-through electrode (Fig. 11a) and gaseous hydrogen on the anode, with a flow-by electrode as shown in Fig. 11b. In this configuration a gaseous species flows in a channel parallel to the electrode and diffuses laterally to the essentially planar electrode surface. (In reality the electrode surface is a $3 \mathrm{D}$ porous zone of catalyst particles and immobilized electrolyte phase, but it behaves essentially as a planar surface on the scale of the electrode assembly.) The porous region of inert solid between the flow channel and the reactive surface acts to distribute gas uniformly to the catalyst and conduct electrons from the electrode to the current collector. The flow-by electrode is well suited to gaseous reactants for two reasons. First, the gaseous reactant stream does not conduct protons, so the reaction must happen at or near the electrolyte phase. Second, the diffusivity of gaseous species are 3 to 4 orders of magnitude higher than liquid-phase species so diffusive mass transfer is able to supply reactants to the electrode at a sufficient rate. Another variant of the flow-by electrode is shown in Fig. 11c, which is used when a solid is electrochemically plated out or dissolved as in the hybrid RFBs. Because the electrode grows during plating, it is not feasible to use a porous electrode as it would become plugged by the plating solid. The so-called single-flow cell reported by Pletcher, Wills and co-workers [2, 71] uses a solid electrode on both the anode and cathode where $\mathrm{Pb}$ and $\mathrm{PbO}$ are stored as plated solids. Ion conduction through the flowing electrolyte phase to the opposing electrode is at a maximum distance in this configuration so ohmic losses are high. Also, the surface area for reaction is at a minimum and equal to the geometric area of the cell. Consequently, this type of flow-by electrode is only used when absolutely necessary, as is the case of the aforementioned solid-plating electrodes.

The use of planar flow-by electrodes with liquid-phase reactants to demonstrate the viability of RFB technology is not uncommon in research papers on the subject [25, 63, 101], but flow-by electrodes, due to their limited surface area and long ion-transport distances, would almost never be preferred over 3D electrodes occupying the same volume. Even in the original RFB patent by Thaller [42], the possibility of using porous, 3D electrodes was included. Many of the tradeoffs of the various geometric placements and concerns can be found in the literature, including the pioneering work of Trainham and Newman [156-158] who examined optimum electrode placement and the tradeoffs between the two transport resistances in Fig. 10.

\subsection{Cell modeling of certain chemistries}

\subsubsection{Iron/chrome}

Fedkiw and Watts developed a mathematical isothermal model to describe the operation of a single anode- 
separator-cathode $\mathrm{Fe} / \mathrm{Cr}$ cell based on electrode theory, redox kinetics, mass transfer, and ohmic effects. The parasitic hydrogen reaction was also considered [159]. It is found that the separator ohmic resistance is the dominant cell resistance followed by the electrolyte ohmic resistance. The kinetic resistance was determined to be negligible at reasonable flow rates. It was predicted that countercurrent electrolyte flow improves global cell performance due to a more uniform current distribution. Decreasing the electrode area tended to decrease the cell current but resulted in high velocity and enhanced mass transfer within the penetration thickness and increased current. This model also provided a method of determined a charge-discharge protocol that obtained the maximum chromium conversion and minimum hydrogen evolution at the same time [159, 160]. Finally, Codina et al. [135] examined the issue of shunt currents when a cell is scaled up to larger sizes and stacks.

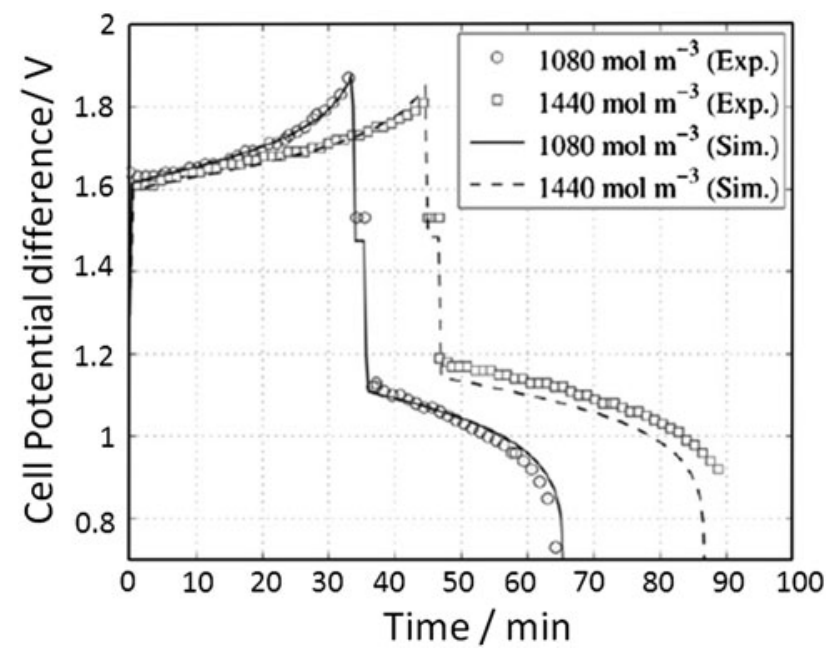

Fig. 12 A comparison between simulated and experimentally obtained cell potential difference. Adapted from Ref. [162] with permission

\subsubsection{All vanadium (VRB)}

Not surprisingly, the VRB is the most often modeled RFB, especially recently [161-167]. Shah et al. developed a twodimensional transient model validated against the experimental diurnal data to study the effects of variation on concentration, electrolyte flowrate, and electrode porosity [168]. They also studied the effects of $\mathrm{H}_{2}$ and $\mathrm{O}_{2}$ evolution on the performance of VRBs by dynamic modeling [162, 164, 165]. As shown in Fig. 12, numerical simulation demonstrates good agreement with the experimental data [162].

Evolved $\mathrm{H}_{2}$ and $\mathrm{O}_{2}$ in the form of bubbles on the negative and positive electrodes, respectively, impact performance through partial occlusion of the electrolyte flow, reduction in the active surface area for reaction, and reduced mass- and charge-transport coefficients. You et al. built a two-dimensional stationary model to describe a single VRB flow cell [167]. They found the decrease in the mass transfer coefficient almost has no effect on the distribution of $\mathrm{V}^{3+}$ concentration and overpotential, as shown in Fig. 13. Li and Hikihara developed a model considering the transient behavior in a VRB and the model was also examined based on the tests of a micro-RFB [169]. They found that the chemical reaction rate is restricted by the attached external electric circuit and the concentration change of vanadium ions depends on the chemical reactions and electrolyte flow.

\subsubsection{Bromine/polysuphide}

Scamman et al. developed a numerical model that can be used for the design and optimization of large-scale bromine/polysulphide RFBs [170, 171]. They used the ButlerVolmer equation to estimate overpotential losses. The crossover of active species and self-discharge was also considered. This model is able to predict the concentration
Fig. 13 Profiles of $\mathrm{V}^{3+}$ concentration (a), and overpotential (b) inside in the negative electrode at $50 \%$ SOC with the applied current density of $40 \mathrm{~mA} / \mathrm{cm}^{2}$. Adapted from Ref. [167] with permission
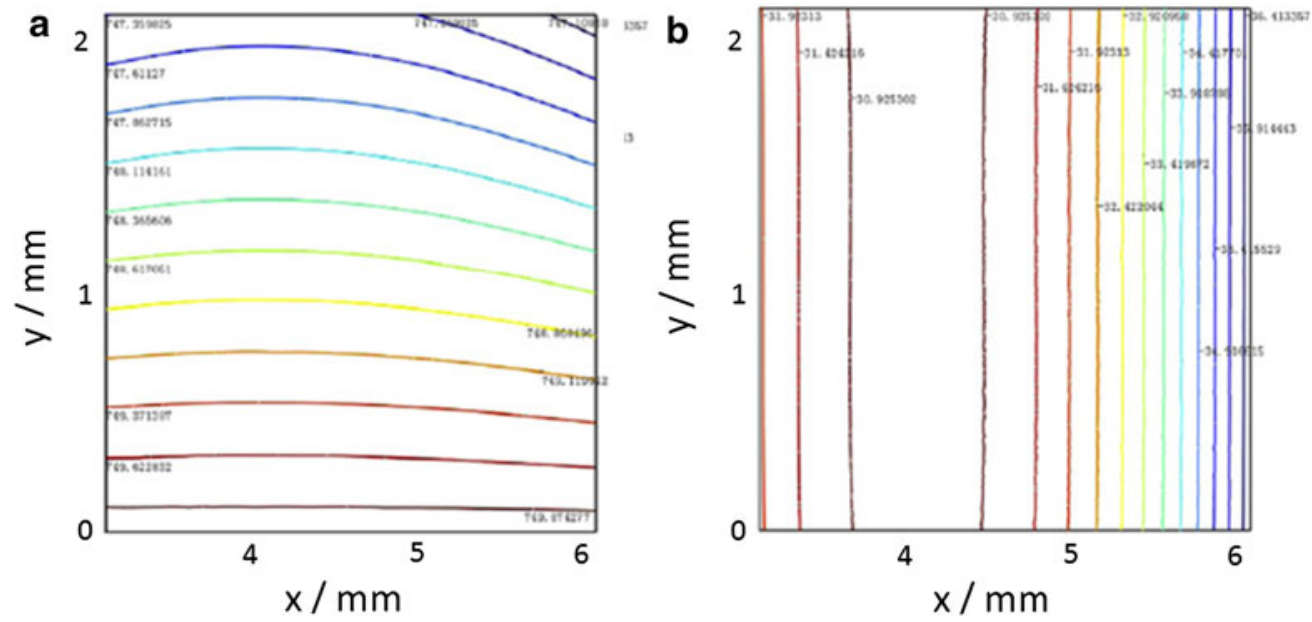
Fig. 14 Reaction-rate profiles for a $\mathrm{Cl}_{2}$ discharging elect rode in a $\mathrm{Zn} / \mathrm{Cl}_{2} \mathrm{RFB}$ at a different flow velocities and $\mathbf{b}$ electrode placement. Adapted from Ref. [176] with permission
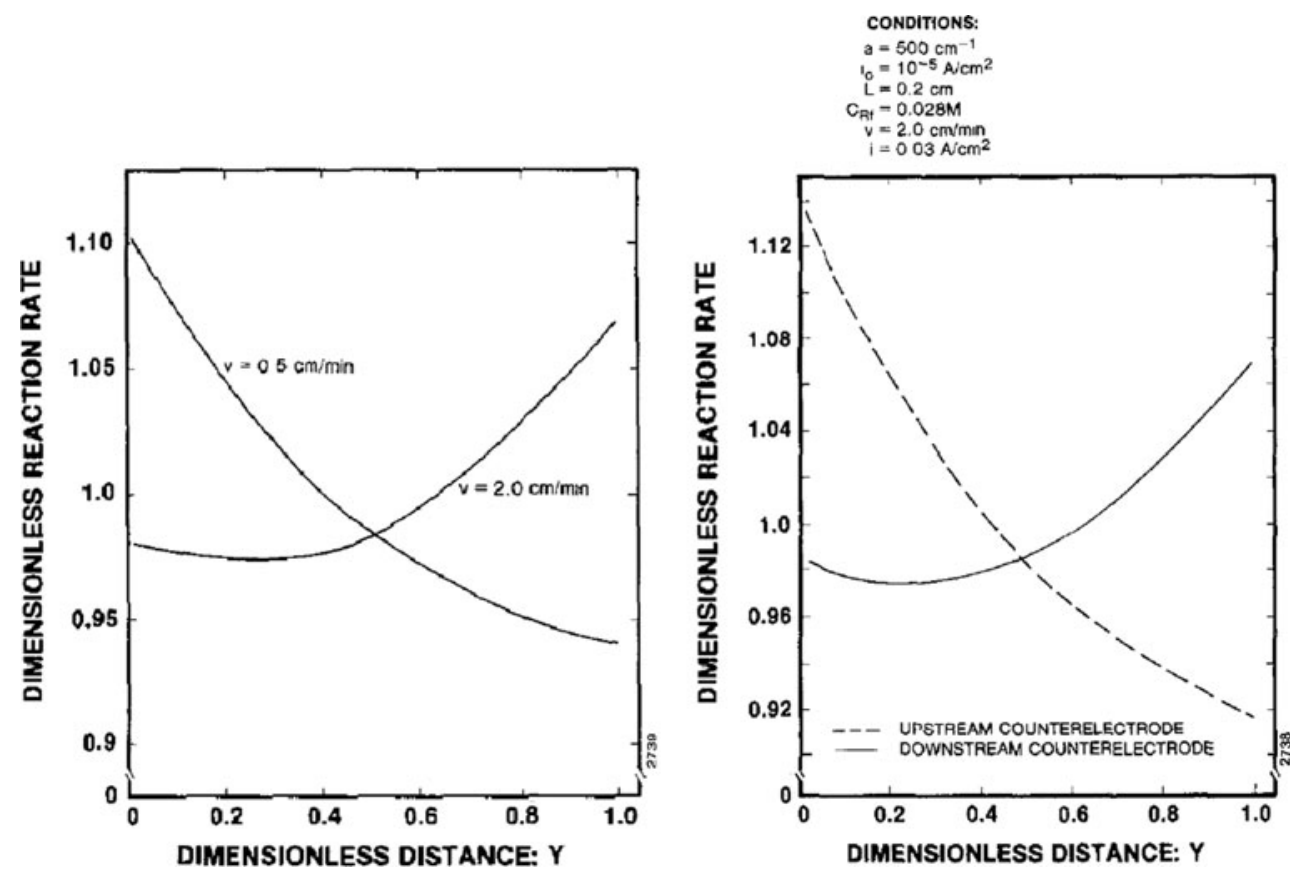

and current variation along the electrode and determine various efficiencies, energy density, and power density in the charge-discharge processes. It is found that the electrochemical rate constants of the bromide and sulphide are $4 \times 10^{-5}$ and $3 \times 10^{-6} \mathrm{~cm} / \mathrm{s}$, respectively.

\subsubsection{Zinc/bromine}

Several models of $\mathrm{Zn} / \mathrm{Br}_{2}$ have been developed to understand the physical phenomena and to determine how cell performance can be improved. These models have been used to investigate the species transport, secondary electrode reactions, and chemical reactions in the bulk electrolyte, including issues during the plating of zinc [172]. Putt [173] and Lee and Selman [174] developed thin diffusion-layer models. These models include electrolyte convection with Butler-Volmer kinetics. Mader and White [61] developed a mathematical model for the cell mainly to predict performance of the cell as a function of architecture and operating conditions. They also used their model to determine the effects of the mass transfer and electrokinetics in the porous bromine electrode on the roundtrip performance of the cell. It was found that the cell efficiency increases with the porous electrode thickness. Jorne and coworkers $[175,176]$ also developed models for the chlorine electrode in a $\mathrm{Zn} / \mathrm{Cl}_{2}$ cell. This electrode is very similar to the bromine one and they showed that the flow from the gap to the zinc electrode can impact the current density and reaction-rate distribution significantly, as well as the placement of the electrode as shown in Fig. 14.

\subsubsection{Zinc/cerium}

Trinidad et al. developed an oxidation-reduction-redoxpotential model to monitor the $\mathrm{Ce}(\mathrm{III}) / \mathrm{Ce}(\mathrm{IV})$ couple [177]

$E_{\mathrm{e}}=E_{\mathrm{e}}^{0}-\frac{R T}{z F}\left\{k t+\ln \left[\frac{\left(C_{\mathrm{Red}}\right)_{0}}{\left(C_{\mathrm{Oxd}}\right)_{0}}+(1-\exp (-k t))\right]\right\}$

The redox potential versus time experimental and model predictions were compared as shown in Fig. 15. The model fit well with the experimental results, showing the model is useful to predict concentration versus time in a simple redox system.

\section{Summary and future research needs}

In this review, we have examined some of the more common RFBs and their individual components and underlying governing physical phenomena. At the present time, there is no "best" RFB chemistry; development continues through industrial and academic research supported by government and industry. It is clear that industrial development of prototypes and working systems has outpaced the fundamental research at this point. Inevitably, for the science to progress and the underlying fundamental problems to be resolved, much more fundamental understanding is required. In terms of transport from a generic, chemistry-agnostic perspective, much more in-depth and fundamental study and characterization of the following 
Fig. 15 a Redox potential versus time for the reduction of $0.043 \mathrm{M}$ of $\mathrm{Ce}(\mathrm{IV})$ in $1 \mathrm{M}$ $\mathrm{H}_{2} \mathrm{SO}_{4}$ for both experimental $(A)$ and calculated $(B)$ values. b Redox potential versus time for the reduction of $0.127 \mathrm{M}$ $\mathrm{Ce}(\mathrm{III})$ in $1 \mathrm{M} \mathrm{H}_{2} \mathrm{SO}_{4}$ and $0.046 \mathrm{M}$ of $\mathrm{Ce}(\mathrm{IV})$. Adapted from Ref. [177] with permission
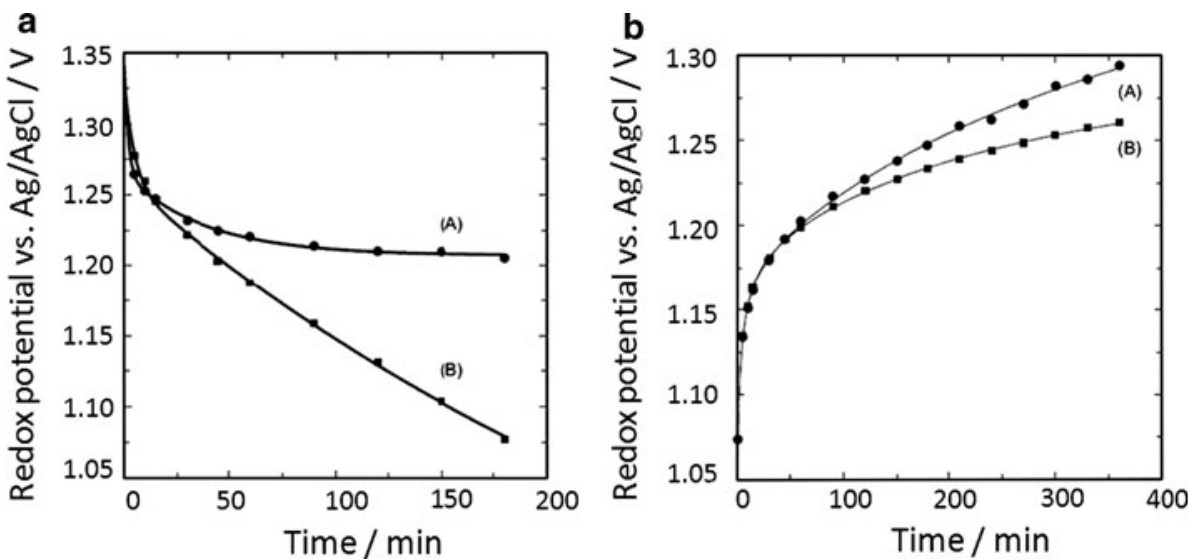

are needed through combined experimental and analytical or computational modeling:

- Charge transport and electrochemical reaction at and near the electrode surface.

- The complex charge transport and nonidealities in the various RFB couples and electrolytes used.

- Species charge transport and crossover in ionicexchange membranes. For many systems, the membranes represent a key limiting component in system feasibility. Low-cost, low-permeability membranes with good ion selectivity, stability, high conductivity, and suitable mechanical properties are required.

- The fluid mechanics and transport of electrolyte through the various electrode and cell architectures including coupled reaction rates and flow distribution to determine optimal electrode structures and properties.

To enable more complete studies in these areas, a new class of RFB diagnostics will also be needed. Another topic requiring future study as the systems with the greatest potential become defined is performance degradation. As in other, more studied, electrochemical-power-conversion systems, many modes of material degradation will likely be associated with transport processes that can be better optimized to promote longevity.

Finally, throughout this review not much mention has been made concerning other components within the RFB system. In particular, the typical solvents and chemistries are inherently highly corrosive due to their high ionic and perhaps protonic concentrations. Their nature makes sealing and material selection for pumps, flowfields, pipes, etc. very difficult and expensive; finding solutions to these issues is necessary for RFB systems to gain entrance to the market.

Acknowledgments This work was partially funded by the Assistant Secretary for Energy Efficiency and Renewable Energy, Office of Fuel Cell Technologies, of the U.S. Department of Energy under contract number DE-AC02-05CH11231; work at UTK was carried out under NSF Early Career Development Award \#0644811.
Open Access This article is distributed under the terms of the Creative Commons Attribution Noncommercial License which permits any noncommercial use, distribution, and reproduction in any medium, provided the original author(s) and source are credited.

\section{References}

1. N. R. C. Committee for the National Academies Summit on America's Energy Future (2008) The national academies summit on America's energy future: summary of a meeting. National Academies Press, Washington, DC

2. EPRI (2004) Energy storage technology valuation primer: techniques for financial modeling. EPRI report 1008810, Palo Alto, CA, December 2004

3. Price A (2005) Proc Inst Civil Eng Civil Eng 158:52

4. EPRI (2002) Handbook of energy storage for transmission or distribution applications. EPRI report 1007189, Palo Alto, CA

5. Ponce De Leon C, Frias-Ferrer A, Gonzalez-Garcia J, Szanto D, Walsh FC (2006) J Power Sources 160:716

6. Li X, Zhang H, Mai Z, Vankelecom I (2011) Energy Environ Sci 4:1147

7. Skyllas-Kazacos M, Chakrabarti MH, Hajimolana SA, Mjalli FS, Saleem M (2011) J Electrochem Soc 158:R55

8. Yang ZG, Zhang JL, Kintner-Meyer MCW, Lu XC, Choi DW, Lemmon JP, Liu J (2011) Chem Rev 111:3577

9. Symons PC, Butler PC (2002) In: Linden D, Reddy TB (eds) Handbook of batteries, 3rd edn. McGraw-Hill, New York

10. Kaldellis JK, Zafirakis D (2007) Energy 32:2295

11. Makarov YV, Loutan C, Ma J, De Mello P (2009) IEEE Trans Power Syst 24:1039

12. Department of Energy Office of Electricity Delivery and Energy Reliability (2011, May) http://www.oe.energy.gov/

13. Department of Energy (2009, May) President Obama Announces \$3.4 billion investment to spur transition to smart grid. http:// www.energy.gov/news2009/8216.html

14. N. Group (2010) Advanced materials and devices for stationary electrical energy storage applications, Nexight Group. http:// energy.tms.org/docs/pdfs/Advanced_Materials_for_SEES_2010.pdf

15. E. A. Committee (2008) Bottling electricity: storage as a strategic tool for managing variability and capacity concerns in the modern grid, Nexight Group. http://www.doe.gov/sites/prod/ files/oeprod/DocumentsandMedia/DRAFT_EAC_Energy_Storage_ Technologies_Report_11-21-08_CLEAN_COPY.pdf

16. Skyllas-Kazacos M, Grossmith F (1987) J Electrochem Soc 134:2950 
17. Remick RJ, Ang PGP (1984) Electrically rechargeable anionically active reduction-oxidation electrical storage-supply system. USA Patent 4485154, November 27, 1984

18. Zhou HT, Zhang HM, Zhao P, Yi BL (2006) Electrochim Acta 51:6304

19. Thaller LH (1974) NASA TM-X-71540

20. Thaller LH (1979) NASA TM-79143, DOE/NASA/1002-79/3

21. Bartolozzi M (1989) J Power Sources 27:219

22. Walsh F (2001) Pure Appl Chem 73:1819

23. Price A, Bartley S, Male S, Cooley G (1999) Power Eng J 13:122

24. Lessner P, Mclarnon F, Winnick J, Cairns E (1992) J Appl Electrochem 22:927

25. Skyllas-Kazacos M, Rychcik M, Robins RG, Fane AG, Green MA (1986) J Electrochem Soc 133:1057

26. Skyllas Kazacos M, Rychick M, Robins RG (1988) All-vanadium redox battery. United States of America Patent

27. Sum E, Rychcik M, Skyllas-Kazacos M (1985) J Power Sources $16: 85$

28. Sum E, Skyllas-Kazacos M (1985) J Power Sources 15:179

29. Kazacos M, Cheng M, Skyllas-Kazacos M (1990) J Appl Electrochem 20:463

30. Skyllas-Kazacos M, Kasherman D, Hong D, Kazacos M (1991) J Power Sources 35:399

31. Rahman F, Skyllas-Kazacos M (1998) J Power Sources 72:105

32. Skyllas-Kazacos M, Peng C, Cheng M (1999) Electrochem Solid-State Lett 2:121

33. Kausar N, Howe R, Skyllas-Kazacos M (2001) J Appl Electrochem $31: 1327$

34. Hagg CM, Skyllas-Kazacos M (2002) J Appl Electrochem 32:1063

35. Sukkar T, Skyllas-Kazacos M (2003) J Membr Sci 222:235

36. Sukkar T, Skyllas-Kazacos M (2004) J Appl Electrochem 34: 137

37. Rahman F, Skyllas-Kazacos M (2009) J Power Sources 189: 1212

38. Skyllas Kazacos M, Kazacos G, Poon G, Verseema H (2010) Int J Energy Res 34:182

39. Vijayakumar M, Burton SD, Huang C, Li L, Yang Z, Graff GL, Liu J, Hu J, Skyllas-Kazacos M (2010) J Power Sources 195:7709

40. Chen J, Wang Q, Wang B (2006) Modern Chem Ind 9:26

41. Shibata A, Sato K (1999) Power Eng J 13:130

42. Shigematsu T, Kumamoto T, Deguchi H, Hara T (2002) Applications of a vanadium redox-flow battery to maintain power quality. Presented at the transmission and distribution conference and exhibition 2002: Asia Pacific. IEEE/PES

43. Mohammadi T, Chieng S, Skyllas Kazacos M (1997) J Membr Sci 133:151

44. Mohammadi T, Skyllas-Kazacos M (1997) J Appl Electrochem 27:153

45. Miyake S, Tokuda N (2002) Battery diaphragm. Google Patents

46. Hennessy TDJ (2007) Telecommunication system incorporating a vanadium redox battery energy storage system. Google Patents

47. Zhao P, Zhang H, Zhou H, Chen J, Gao S, Yi B (2006) J Power Sources 162:1416

48. Skyllas-Kazacos M (2003) J Power Sources 124:299

49. Skyllas-Kazacos M, Menictas C, Kazacos M (1996) J Electrochem Soc 143:L86

50. Skyllas-Kazacos M, Limantari Y (2004) J Appl Electrochem 34:681

51. Vafiadis H, Skyllas-Kazacos M (2006) J Membr Sci 279:394

52. Chang BJ, Garcia CP, Johnson DW, Bents DJ, Scullin VJ, Jakupca IJ (2007) J Fuel Cell Sci Technol 4:497

53. Grigoriev SA, Millet P, Porembsky VI, Fateev VN (2011) Int J Hydrogen Energy 36:4164
54. Li XJ, Xiao Y, Shao ZG, Yi BL (2010) J Power Sources 195: 4811

55. Mitlitsky F, Myers B, Weisberg AH (1998) Energy Fuels 12:56

56. Neyerlin KC, Gu WB, Jorne J, Gasteiger HA (2006) J Electrochem Soc 153:A1955

57. Kim JT, Jorne J (1977) J Electrochem Soc 124:1473

58. Kosek JA, Laconti AB (1988) J Power Sources 22:293

59. Livshits V, Ulus A, Peled E (2006) Electrochem Commun 8:1358

60. Cathro KJ, Cedzynska K, Constable DC (1987) J Power Sources $19: 337$

61. Mader MJ, White R (1986) J Electrochem Soc 133:1297

62. Hromadova M, Ronald Fawcett W (2001) J Phys Chem A 105:104

63. Lim HS, Lackner AM, Knechtli RC (1977) J Electrochem Soc 124:1154

64. R. Ltd. (2011) URL: http://www.redflow.com.au/. Accessed May 2011

65. Jorne J, Kim JT, Kralik D (1979) J Appl Electrochem 9:573

66. Zito R (1973) US Patent 3719526

67. Hruska LW, Savinell RF (1981) J Electrochem Soc 128:18

68. Dougherty, B, Clarke RL, Harrion S, Millington PJ, Mohanta S (2009) Cerium batteries. U.S. Patent

69. P. Ltd. (2011) http://plurionsystems.com/tech_flow_advantages.html

70. Leung P, De León CP, Walsh F (2011) Electrochem Commun 13:770

71. Raju T, Basha CA (2008) Ind Eng Chem Res 47:8947

72. Crompton TR (ed) (2000) Elsevier science and technology books, vol 14, 3rd edn. Newnes, Boston

73. Fang B, Iwasa S, Wei Y, Arai T, Kumagai M (2002) Electrochim Acta 47:3971

74. Matsuda Y, Tanaka K, Okada M, Takasu Y, Morita M, Matsumura-Inoue T (1988) J Appl Electrochem 18:909

75. Chakrabarti M, Dryfe R, Roberts E (2007) Electrochim Acta 52:2189

76. Yamamura T, Shiokawa Y, Yamana H, Moriyama H (2002) Electrochim Acta 48:43

77. Liu Q, Sleightholme AES, Shinkle AA, Li Y, Thompson LT (2009) Electrochem Commun 11:2312

78. Liu Q, Shinkle AA, Li Y, Monroe CW, Thompson LT, Sleightholme AES (2010) Electrochem Commun 12:1634

79. Sleightholme AES, Shinkle AA, Liu Q, Li Y, Monroe CW, Thompson LT (2011) J Power Sources 196:5742

80. Shinkle AA, Sleightholme AES, Griffith LD, Thompson LT, Monroe CW (2011) J Power Sources (in press)

81. Kraytsberg A, Ein-Eli Y (2011) J Power Sources 196:886

82. Chiang Y, Carter WC, Ho B, Duduta M (2009) High energy density redox flow device. WO Patent WO/2009/151639

83. Duduta M, Ho B, Wood VC, Limthongkul P, Brunini VE, Craig Carter W, Chiang Y-M (2011) Adv Energy Mater 1

84. Vetter KJ (1967) Electrochemical kinetics: theoretical and experimental aspects. Academic Press, New York

85. Bard AJ, Faulkner LR (2000) Electrochemical methods: fundamentals and applications. Wiley, Hoboken

86. Gerischer H (1960) Z Physik Chem. Neue Forschung 26:223

87. Newton MD, Smalley JF (2007) Phys Chem Chem Phys 9:325

88. Bard AJ (2010) J Am Chem Soc 132:7559

89. Nagy Z, Hung NC, Yonco RM (1991) J Electrochem Soc 138:2032

90. Randles JEB, Somerton KW (1952) Trans Faraday Soc 48:937

91. Gattrell M, Qian J, Stewart C, Graham P, Macdougall B (2005) Electrochim Acta 51:395

92. Zhong S, Kazacos M, Burford R, Skyllas-Kazacos M (1991) J Power Sources 36:29

93. Faita G, Fiori G, Mussini T (1978) Electrochim Acta 13:1765

94. Mastragostino M, Gramellini C (1985) Electrochim Acta 30:373 
95. Haddadi-Asl V, Kazacos M, Skyllas-Kazacos M (1995) J Appl Electrochem 25:29

96. Han P, Wang H, Liu Z, Chen X, Ma W, Yao J, Zhu Y, Cui G (2011) Carbon 49:693

97. Hung NC, Nagy Z (1987) J Electrochem Soc 134:2215

98. Kinoshita K (1988) Carbon. Electrochemical and physiochemical properties. Wiley, New York

99. Rosseinsky DR (1965) Chem Rev 65:467

100. Inoue M, Tsuzuki Y, Iizuka Y, Shimada M (1987) J Electrochem Soc 134:756

101. De Leon CP, Reade GW, Whyte I, Male SE, Walsh FC (2007) Electrochim Acta 52:5815

102. Thaller LH (1976) Electrically rechargeable redox flow cell. US patent 3996064

103. EISA (2007) Energy independence and security act of 2007, in PL 110-140, United States of America

104. Shao YY, Wang XQ, Engelhard M, Wang CM, Dai S, Liu J, Yang ZG, Lin YH (2010) J Power Sources 195:4375

105. Chiang YM, Bazzarella R (2010) Fuel system using redox flow battery. WO Patent WO/2010/118060

106. Van Brakel J, Heertjes PM (1974) Int J Heat Mass Transf 17:1093

107. Carta R, Palmas S, Polcaro AM, Tola G (1991) J Appl Electrochem 21:793

108. Dullien FaL (1992) Porous media: fluid transport and pore structure, 2nd edn. Academic Press, Inc., New York

109. Gostick JT, Fowler MW, Pritzker MD, Ioannidis MA, Behra LM (2006) J Power Sources 162:228

110. Newman J (1995) J Electrochem Soc 142:97

111. Roy A, Hickner MA, Einsla BR, Harrison WL, Mcgrath JE (2009) J Polym Sci A 47:384

112. Sankir M, Kim YS, Pivovar BS, Mcgrath JE (2007) J Membr Sci 299:8

113. Gostick JT, Ioannidis MA, Fowler MW, Pritzker MD (2010) In: Wang CY, Pasaogullari U (eds) Modern aspects of electrochemistry, vol 49. Springer, Berlin

114. Newman J, Thomas-Alyea KE (2004) Electrochemical systems, 3rd edn. Wiley, New York

115. Bird RB, Stewart WE, Lightfoot EN (2002) Transport phenomena, 2nd edn. Wiley, New York

116. Einstein A (1905) Ann Physik 17:549

117. Nernst W (1888) Zeitschrift fuer Physikalische Chemie 2:613

118. Weber AZ, Newman J (2004) Chem Rev 104:4679

119. Bear J (1988) Dynamics of fluids in porous media. Dover Publications Inc, New York

120. Chen YWD, Bard AJ (1984) Inorg Chem 23:2175

121. Sun B, Sykllaskazacos M (1992) Electrochim Acta 37:1253

122. Zhao P, Zhang HM, Zhou HT, Yi BL (2005) Electrochim Acta 51:1091

123. Sun B, Skyllaskazacos M (1992) Electrochim Acta 37:2459

124. Joerissen L, Garche J, Fabjan C, Tomazic G (2004) J Power Sources 127:98

125. Duarte MME, Pilla AS, Sieben JM, Mayer CE (2006) Electrochem Commun 8:159

126. Yan A, Xiao X, Kulaots I, Sheldon BW, Hurt RH (2006) Carbon $44: 3116$

127. Sioda R (1977) Electrochim Acta 22:439

128. Cano J, Böhm U (1977) Chem Eng Sci 32:213

129. Li L, Kim S, Wang W, Vijayakumar M, Nie Z, Chen B, Zhang J, Xia G, Hu J, Graff G (2011) Adv Energy Mater 1:394

130. Ridgway P, Cho K, Battaglia VS, Weber AZ, Srinivasan V (2011) Redox kinetics of the bromine-bromide reaction for flow batteries. Presented at the 220th meeting of the Electrochemical Society, Boston, MA
131. Horne C, Kinoshita K, Hickey DB (2010) Redox flow battery system for distributed energy storage. United States Patent $12 / 498103$

132. Schroll CR (1984) Manifold dielectric barrier for a fuel cell electrical power generation system. United States of America Patent

133. Katz M (1978) J Electrochem Soc 125:515

134. Zhou G, Chen L, Seaba J (2006) Proceedings of the 4th international ASME conference on fuel cell science, engineering, and technology, Pts A and B, p 863

135. Codina G, Aldaz A (1992) J Appl Electrochem 22:668

136. Codina G, Perez JR, Lopezatalaya M, Vazquez JL, Aldaz A (1994) J Power Sources 48:293

137. Kanari K, Nozaki K, Kaneko H, Hashimoto T, Fujii T (1991) Denki Kagaku 59:237

138. Mauritz KA, Moore RB (2004) Chem Rev 104:4535

139. Weber AZ, Newman J (2004) J Electrochem Soc 151:A311

140. Pintauro PN, Bennion DN (1984) Ind Eng Chem Fundam 23:230

141. Weber AZ, Delacourt C (2008) Fuel Cells 8:459

142. Delacourt C, Newman J (2008) J Electrochem Soc 155:B1210

143. Xi J, Wu Z, Qiu X, Chen L (2007) J Power Sources 166:531

144. Teng X, Zhao Y, Xi J, Wu Z, Qiu X, Chen L (2009) J Power Sources 189:1240

145. Jia C, Liu J, Yan C (2010) J Power Sources 195:4380

146. Qiu J, Zhai M, Chen J, Wang Y, Peng J, Xu L, Li J, Wei G (2009) J Membr Sci 342:215

147. Qiu J, Zhao L, Zhai M, Ni J, Zhou H, Peng J, Li J, Wei G (2008) J Power Sources 177:617

148. Chen D, Wang S, Xiao M, Meng Y (2010) J Power Sources 195:2089

149. Chen D, Wang S, Xiao M, Meng Y (2010) Energy Convers Manag 51:2816

150. Chen D, Wang S, Xiao M, Meng Y (2009) Energy Environ Sci 3:622

151. Teng X, Zhao Y, Xi J, Wu Z, Qiu X, Chen L (2009) J Membr Sci 341:149

152. Sang S, Wu Q, Huang K (2007) J Membr Sci 305:118

153. Luo Q, Zhang H, Chen J, Qian P, Zhai Y (2008) J Membr Sci 311:98

154. Newman J, Tiedemann W (1975) AIChE J 21:25

155. Yue L, Li WS, Sun FQ, Zhao LZ, Xing LD (2010) Carbon 48:3079

156. Trainham JA, Newman J (1977) J Electrochem Soc 124:1528

157. Trainham JA, Newman J (1977) J Appl Electrochem 7:287

158. Trainham JA, Newman J (1978) J Electrochem Soc 125:58

159. Fedkiw PS, Watts RW (1984) J Electrochem Soc 131:701

160. Lopez-Atalaya M, Codina G, Perez J, Vazquez J, Aldaz A (1992) J Power Sources 39:147

161. Al-Fetlawi H, Shah AA, Walsh FC (2009) Electrochim Acta 55:78

162. Al-Fetlawi H, Shah AA, Walsh FC (2010) Electrochim Acta 55:3192

163. Knehr K, Kumbur E (2011) Electrochem Commun 13:342

164. Shah A, Al-Fetlawi H, Walsh F (2010) Electrochim Acta 55:1125

165. Shah A, Tangirala R, Singh R, Wills RGA, Walsh FC (2011) J Electrochem Soc 158:A671

166. Vynnycky M (2011) Energy 36:2242

167. You D, Zhang H, Chen J (2009) Electrochim Acta 54:6827

168. Shah A, Watt-Smith M, Walsh F (2008) Electrochim Acta 53:8087

169. Li M, Hikihara T (2008) IEICE Trans Fundam Electron Commun Comput Sci E91A:1741

170. Scamman DP, Reade GW, Roberts EPL (2009) J Power Sources 189:1220 
171. Scamman DP, Reade GW, Roberts EPL (2009) J Power Sources 189:1231

172. Evans TI, White RE (1987) J Electrochem Soc 134:2725

173. Putt R (1979) Assessment of technical and economic feasibility of zinc/bromine batteries for utility load-levelling. EPRI report Em-1059, Project 635-1, Palo Alto, CA, Appendix M
174. Lee J, Selman J (1982) J Electrochem Soc 129:1670

175. Jorne J (1982) J Electrochem Soc 129:2251

176. Roayaie E, Jorne J (1985) J Electrochem Soc 132:1273

177. Trinidad P, De Leon CP, Walsh F (2008) J Environ Manag 88:1417 